\title{
On the Potential Remedies for License Plate Rationing
}

\author{
$\mathrm{Yu}(\mathrm{Marco}) \mathrm{Nie}^{* 1}$ \\ ${ }^{1}$ Department of Civil and Environmental Engineering \\ Northwestern University \\ 2145 Sheridan Road, Evanston, IL 60208
}

January 4, 2017

\begin{abstract}
This paper analyzes three travel demand management policies designed to correct the shortcomings of license plate rationing (LPR). The first policy couples LPR with a new vehicle quota scheme that directly controls auto ownership. The other two policies turn the driving permit into a tradable commodity. They differ, however, in that one policy ties the permit to the license plate while the other bestows all travelers with equal driving permits. All new policies may be viewed as "derivatives" of LPR because they share some key features: simplicity and revenue neutrality. Using a conceptual model that considers two modes (transit and driving) and user heterogeneity, we analyze user equilibrium solutions under each new policy, and for policies based on permit trading, introduce and characterize a function that links individuals' trading behavior to their value of time. Our analysis and numerical experiments show that giving tradable permits to all travelers is more efficient than the other alternatives. Under this policy, travelers who decide to own automobiles will acquire enough permits from those who do not so that the former can drive without any restriction. Consequently, the permit each traveler should receive can be easily determined from the ratio between a desired highway flow level and the total demand. Importantly, when the desired flow level equals the system optimal flow, the policy is revenue-neutral and first-best under idealized conditions.
\end{abstract}

Keywords: license plate rationing; travel demand management; permit trading; user heterogeneity; new vehicle quota

\section{Introduction}

Travel demand management (TDM) policies have been a recurrent theme in transportation systems analysis (e.g. Beckmann et al., 1956; Ferguson, 2000; Gärling et al., 2002; Small and Verhoef, 2007). These policies are widely considered useful tools for solving the chronic traffic congestion problem in big cities, arguably the "Holy Grail" of the field. They also increasingly appear in the discussions of sustainable cites since traffic congestion contributes to excessive energy consumption and emissions of green house gas and air pollutants (Schrank et al., 2012; DOE, 2014).

Managing travel demand always involves, in one way or another, inducing or forcing behavioral/attitudinal changes regarding an essential public good, i.e., roads. Not surprisingly, the public often meets any proposals of TDM policies with suspicion and hesitation, if not outright rejection. Congestion pricing, for example,

${ }^{*}$ Corresponding author, E-mail: y-nie@ northwestern.edu; Phone: 1-847-467-0502.

(C) 2017. This manuscript version is made available under the Elsevier user license http://www.elsevier.com/open-access/userlicense/1.0/ 
has only been successfully implemented in a handful of cities in limited forms (Lindsey et al., 2012), despite transportation economists had appraised and advocated the policy passionately for decades, supported by convincing theoretical arguments (Vickrey, 1969; Hau, 1992; Yang and Huang, 2004; Tsekeris and Vos, 2009; de Palma and Lindsey, 2011). High profile failures such as Hong Kong in 1987 (Hau, 1990), Edinburgh in $2006^{1}$ and New York in $2007^{2}$, serve as vivid reminders of the extraordinary challenge to win public support for the policy.

Interestingly, a seemingly more intrusive TDM policy, known as license plate rationing (LPR), has begun to gain popularity in recent years, mostly in developing countries. The first large scale LPR was implemented by the Mexico City in 1989 (Eskeland and Feyzioglu, 1997; CA, 2007), which bans each car from being driven on a specific day of the week, based on the last digit of its license plate number, hence the name. Since then, at least seven cities have implemented similar policies: Manila, Philippines (1996, see GUETA and GUETA, 2013), Sao Paulo, Brazil (1997, see CA, 2007), Bogota, Columbia (2000, see CA, 2007), and four Chinese cities (Beijing, Chengdu, Tianjin, Hangzhou, all adopted the policy since 2011, see Nie, 2016). However, the long-term effectiveness and efficiency of LPR policies have been repeatedly challenged in the literature, empirically and theoretically.

Eskeland and Feyzioglu (1997) observed that the policy failed to reduce driving in the Mexico City. GUETA and GUETA (2013) made a similar observation for the city of Manila. Later, Davis (2008) found no evidence that the policy improved air quality in the Mexico City, a promise based on which the policy was sold to the residents. For Beijing, a study using data from 2009 to 2014 found that, since LPR went into effect in 2011, traffic conditions have been significantly improved in the restricted time period, with travelers shifting to buses and taxis ${ }^{3}$. Yet, Nie (2016) showed that the positive effect of LPR has been more than offset by the steady growth in the auto ownership by the end of 2014. A report published by the Regional Plan Association of New York City (Zupan et al., 2007) compares LPR with congestion pricing, and concludes that LPR is far less effective in generating congestion relief and pollution reduction. The findings of the empirical studies are also echoed by theoretical analysis. Eskeland and Feyzioglu (1997) suggest that LPR may lead to high welfare losses because it could curtail trips with high willingness to pay. Zhu et al. (2013) show that when the induced demand is considered LPR always leads to welfare losses. Wang et al. (2010) characterize equilibrium solutions under LPR, using a general network model that allows travelers to acquire additional vehicles to bypass the restriction. They show that the policy is Pareto-improving if no one-car traveler's average travel time increases after LPR is implemented, a condition not particularly easy to fulfill, especially if many desire to buy the second car. Recently, using a simplified model of Wang et al. (2010), Nie (2016) shows that LPR may impact the ability of other TDM policies to maximize system efficiency, when jointly implemented.

In light of the evidently negative picture, one cannot help but wonder why policy makers seem more willing and able to implement LPR than congestion pricing ${ }^{4}$. While many factors could be at play, two are likely dominating the others. The first has to do with the fact that LPR is relatively easy and cheap to implement and enforce. It does not require dedicated infrastructure and complicated collection/redistribution schemes essential to congestion pricing. Second and perhaps more important, LPR is revenue neutral and hence likely to be perceived fairer by the public, because all travelers, rich or poor, are subject to the same driving restriction. In comparison, congestion pricing is often considered a regressive policy that benefits the

\footnotetext{
${ }^{1}$ http://news.bbc.co.uk/2/hi/uk_news/scotland/4287145.stm, last visited on 6/21/2015.

${ }^{2}$ http://www.nytimes.com/2007/07/17/nyregion/17congestion.html?_r=0, last visited on 6/21/2015.

${ }^{3}$ Yang, Jun, Fangwen Lu and Ping Qin. 2016. How does a driving restriction affect transportation patterns? The medium-run evidence from Beijing. Environment for Development, Discussion paper 16-10, http://www.rff.org/files/document/file/EfD-DP-1610.pdf.

${ }^{4}$ In fact, since 2007 congestion pricing has been considered by various Chinese cities (e.g. Shenzhen, Guangzhou, Shanghai and Beijing, see Nie, 2016). Yet, so far not a single one has adopted it. LPR seems to be received much better, however.
} 
rich at the expense of the poor (Evans, 1992; Arnott et al., 1994; Hau, 1998; Taylor and Kalauskas, 2010).

Motivated by the practicality and implementability of LPR, this paper aims to explore potential remedies that would help overcome the known shortcomings of the policy. In seeking alternative policies, the primary criterion is to keep the key features of LPR: simplicity and revenue neutrality. Specifically, the following three policies will be considered:

1. LPR coupled with new vehicle quota (NVQ) (Chin and Smith, 1997) ${ }^{5}$. The idea is that coupling LPR with NVQ would help curtail the growth of auto ownership triggered by LPR, hence improve its effectiveness.

2. LPR coupled with trading among auto owners. The promise of trading the "permit" to drive is that for some travelers, desirable access to driving may be achieved at a lower cost by purchasing such permits than the second car.

3. Permit rationing and trading among all travelers. This policy aims to avoid making the right to drive as a de facto "entitlement" of auto owners, which not only is unfair, but could also induce excessive demand for auto ownership.

The above policies will be analyzed using the same model as in Nie and Liu (2010) and Nie (2016), which explicitly considers mode choice and user heterogeneity. The model is derived from that of Wang et al. (2010), but reduces its general network representation to a single road for better analytical tractability.

The idea of allowing all travelers to trade driving permits is inspired by recent studies on tradable credit schemes (TCS) (see e.g. Verhoef et al., 1997; Viegas, 2001; Yang and Wang, 2011; Nie, 2012; Wang and Yang, 2012; Nie, 2013; Nie and Yin, 2013; Xiao et al., 2013; Ye and Yang, 2013). One can argue that the second and third policies above may be viewed as variants of TCS that are coarser but are easier to implement and enforce. There are notable differences, however. To the best of our knowledge, credit trading only in a subset of all travelers has not been explored in the literature. A more important distinction of the proposed analysis is the consideration of heterogenous trading behavior. Specifically, the number of credits bought/sold is assumed to depend on individuals' value of time (modeled as a continuously distributed random variable) through a so-called trading function. We shall characterize this trading function and reveal its differences under the two trading policies. Our analytical and numerical results will show that the third policy above is the most promising of the three in terms of alleviating traffic congestion and improving social welfare.

The rest of the paper is organized as follows. Section two briefly reviews the model. Sections three to five analyze the three new LPR-based TDM policies to establish theoretical results that help qualitatively assess their effects. Results of numerical experiments are discussed in Section six. Section seven concludes the study with a summary of findings and future research topics.

\section{The model}

For completeness, we briefly review the model in this section. The reader is referred to Nie and Liu (2010) and Nie (2016) if more details are desired.

Consider a single origin-destination (O-D) network that has a fixed demand $d$ and is connected by two routes that essentially represent the choice of two modes: riding transit and driving on highway with a private automobile. The travel time on the highway is denoted as $\tau(q)$, which is a strictly increasing and convex function of the highway flow $q$. The transit travel time $\gamma$ is assumed to be a constant. $c_{A}$ and $c_{T}$ denote

\footnotetext{
${ }^{5}$ The policy had been adopted by several Chinese cities, including Beijing and Shanghai (see Wang, 2010; Nie, 2016).
} 
the user costs associated with driving on highway and riding transit respectively. Let $\phi$ be the amortized cost of owning a vehicle, referred to as the auto capital cost hereafter. To simplify the analysis, we assume $\gamma>\tau(0), c_{A}>c_{T}$ (Nie and Liu, 2010).

Travelers are heterogeneous in the sense that the value of time (VOT, denoted by $\beta$ ) is different. The distribution of $\beta$ among travelers is denoted as $F(\beta)$, where $F\left(\beta_{0}\right)$ is the total number of travelers whose value of time $\beta \geq \beta_{0}$. Accordingly, $F\left(\beta_{L}\right)=d$ and $F\left(\beta_{U}\right)=0$, where $\beta_{L}$ and $\beta_{U}$ are minimum and maximum VOT among all travelers, and $\beta_{L} \geq 0$. For simplicity, we shall also assume that $F(\cdot) \in \mathcal{F}$, where $\mathcal{F}$ is a class of continuous and strictly decreasing function defined on $\left[\beta_{L}, \beta_{U}\right]$. Thus, any individual can be identified according to $\beta$ or a ranking in the population $q=F(\beta)$. Conversely, for any given $q, F^{-1}(q)$ identifies a unique $\beta$. For homogeneous travelers with the same $\beta, F^{-1}$ would be a horizontal line between 0 and $d$ with a height of $\beta$.

The total travel cost of an individual is a combination of the monetary value of travel time, operating cost and auto capital cost (if any). When the highway flow is $q$, the travel cost of an individual with a VOT $\beta$ is

$$
\begin{aligned}
& u_{A}=\beta \tau(q)+c_{A}+\phi, \text { and } \\
& u_{T}=\beta \gamma+c_{T},
\end{aligned}
$$

for driving and using transit, respectively. Following the standard assumption in transportation (e.g. Wardrop, 1952), we assume that travelers always choose either of the modes to minimize their own travel cost. Accordingly, the bi-modal network admits a user equilibrium (UE) flow pattern at which a traveler $q_{e}$ is subject to an identical cost whether s/he chooses transit or driving. Thus, ignoring corner solutions ${ }^{6}$, we can find $q_{e} \in[0, d]$ such that

$$
F^{-1}\left(q_{e}\right) \tau\left(q_{e}\right)+c_{A}+\phi=\gamma F^{-1}\left(q_{e}\right)+c_{T}
$$

Let $\beta_{e}=F^{-1}\left(q_{e}\right), \tau_{e}=\tau\left(q_{e}\right), \Delta c=c_{A}+\phi-c_{T}>0$ (as per the assumption), and rewrite the above equation as

$$
\left(\gamma-\tau_{e}\right) \beta_{e}=\Delta c
$$

The traveler $q_{e}$ is hereafter referred to as the indifferent traveler at UE. Travelers with $\beta>\beta_{e}$ will drive whereas travelers with $\beta<\beta_{e}$ will ride transit. The total system time and cost can be written as

$$
\hat{G} \equiv \int_{0}^{q} F^{-1}(w) \tau(q) d w+\int_{q}^{d} F^{-1}(w) \gamma d w+\left(c_{A}+\phi\right) q+c_{T}(d-q)
$$

To find $q$ that minimizes $\hat{G}$, setting the derivative with respect to $q$ we have

$$
\frac{d \hat{G}}{d q}=F^{-1}(q) \tau(q)+\tau(q)^{\prime} \int_{0}^{q} F^{-1}(w) d w-\gamma F^{-1}(q)+\Delta c=0 .
$$

Let $q_{s}$ be the solution to the above equation, the system cost at SO is denoted as $\hat{G}\left(q_{s}\right)$. Compared to (2), we see that charging a toll on highway equal to

$$
\mu_{s}=\tau\left(q_{s}\right)^{\prime} \int_{0}^{q_{s}} F^{-1}(w) d w
$$

${ }^{6}$ According to Nie and Liu (2010), the following condition excludes corner solutions

$$
(\gamma-\tau(d)) F^{-1}(d)<\Delta c<(\gamma-\tau(0)) F^{-1}(0)
$$




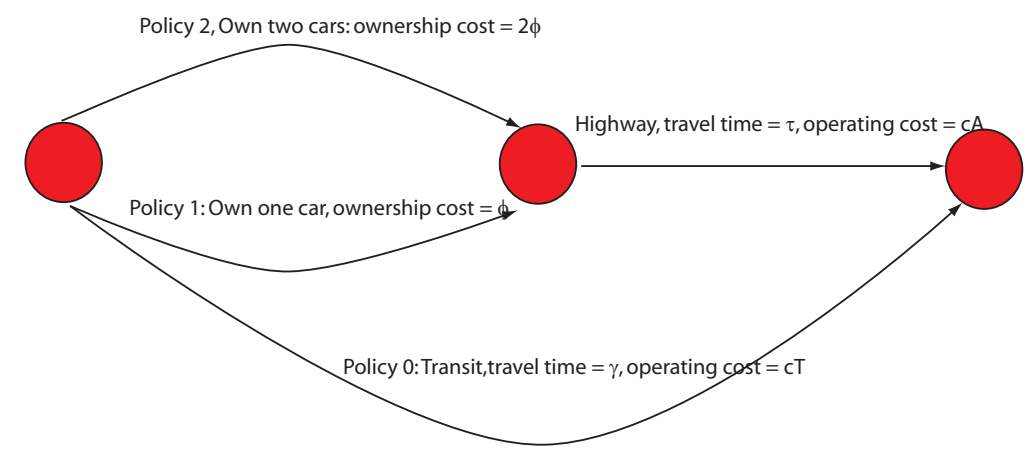

Figure 1: License plate rationing considering vehicle ownership decision

would internalize the externality and minimize the system cost.

Under an LPR policy, the authority dictates that travelers choosing to drive can only drive on a fraction of all days depending on the last digit of their license plate. This fraction, denoted as $\lambda \in[0,1]$, is called the rationing ratio hereafter. Note that $\lambda=1$ and 0 represents no restriction and full restriction, respectively. Travelers can, however, game the LPR policy by acquiring a second vehicle. As a result, the initial traffic reduction benefit of LPR is often quickly eroded by the increase in auto ownership. Nie (2016) shows that the efficiency of the LPR policy degrades substantially when travelers have access to the second car.

The following sections will analyze three policies aiming to address the inherent failure of the LPR policy. The first policy directly restricts the auto ownership, while the second allows auto owners to trade the permits to drive given by the licence plate. In both policies, we assume $\lambda \geq 0.5$ so that nobody needs to buy more than two cars, since odd-even rationing $(\lambda=0.5)$ is the most restrictive form of LPR in practice. It is worth emphasising that no attempt is made here to identify the optimal parameters (e.g., the optimal $\lambda$ that minimizes the total system cost) in each policy. Instead, the focus is to understand the welfare effects of the policies under a range of restriction scenarios. The reader is referred to Nie (2016) for discussions on system optimal solutions under LPR.

\section{LPR with new vehicle quota (LPR-NVQ)}

This section considers a policy that couples LPR with a new vehicle quote (NVQ) scheme to directly restrict auto ownership. Beijing, for example, implemented both policies, even though in Beijing's case the adoption of NVQ preceded that of LPR. The question asked here is whether or not NVQ can help improve LPR's efficiency.

Let $R=\{0,1,2\}$ be the set of possible choices, corresponding to owning no cars (transit is the only option), owning one car (driving only when permitted) and owning two cars (driving is always available), respectively. These choices may be represented by a network depicted in Figure 1, where the "highway" receives all vehicular traffic generated by travelers who are allowed to drive. Consequently, the problem may be viewed as a traffic assignment problem with an elastic demand for the highway being determined by the VOT distribution function. Wang et al. (2010) showed that this assignment problem can be formulated as a variational inequality problem, and the solution existence can then be established from the continuity of the cost functions, and the compactness of the feasible set.

Let $u_{r}$ and $f_{r}$ be the cost and flow associated with the choice $r \in R$, and $u_{r}$ for a given $\beta$ is defined as 
follows.

$$
\begin{aligned}
& u_{1}(\beta)=\lambda\left(\beta \tau(q)+c_{A}\right)+(1-\lambda)\left(\beta \gamma+c_{T}\right)+\phi, \\
& u_{2}(\beta)=\beta \tau(q)+c_{A}+2 \phi, \\
& u_{0}(\beta)=\beta \gamma+c_{T} .
\end{aligned}
$$

We also note that in this case the highway flow

$$
q=f_{2}+\lambda f_{1} .
$$

We assume that the NVQ scheme will introduce the following constraint:

$$
f_{1}+2 f_{2} \leq K_{0} f_{e}
$$

where $K_{0} \geq 1$ is the desired vehicle control target and $f_{e}$ is the UE flow when $\lambda=1.0$. The right hand side of the inequality represents the total number of cars in the system. Since NVQ cannot remove the vehicles already on the road when LPR is implemented, it typically sets the control target based on a desired growth rate, using $f_{e}$ (the status quo) as a reference point. In practice, such a target may be chosen annually according to the increase in the number of travelers and the desired split between transit and driving. Since the dynamic changes in travel demand and transportation supply are not explicitly modeled here, we do not attempt to optimize the choice of $K_{0}$. Rather, the focus is to examine if imposing such a constraint would be beneficial compared to alternative polices.

Let $\nu$ be the multiplier associated with Constraint (8), the complementarity requires

$$
\nu \geq 0 ; \nu\left(f_{1}+2 f_{2}-K_{0} f_{e}\right)=0
$$

We note that $\nu$ may be interpreted differently according to how the NVQ is implemented. If the new licence plates are auctioned off (as in the case of Singapore and Shanghai), $\nu$ can be interpreted as the lowest bid that can win a license. If the licenses are given away through a lottery (as in the case of Beijing), $\nu$ is simply a shadow cost imposed by the capacity constraint (8), which is the welfare loss of those who have the willingness to pay for the second car but cannot due to NVQ.

The UE conditions that incorporate the multiplier are ${ }^{7}$

$$
\begin{aligned}
f_{1} \in(0, d) & \rightarrow \exists \beta_{1} \in\left[\beta_{L}, \beta_{U}\right], \text { s.t. } & & u_{1}\left(\beta_{1}\right)+\nu=u_{0}\left(\beta_{1}\right) \\
f_{2}>0 & \rightarrow \exists \beta_{2} \in\left[\beta_{L}, \beta_{U}\right], \text { s.t. } & & u_{1}\left(\beta_{2}\right)+\nu=u_{2}\left(\beta_{2}\right)+2 \nu
\end{aligned}
$$

where $\beta_{1}=F^{-1}\left(f_{1}+f_{2}\right), \beta_{2}=F^{-1}\left(f_{2}\right)$. The UE solutions can be obtained from the above conditions using a simple trial and error method presented in Appendix A.

\section{LPR with trading among auto owners}

LPR essentially bestows permits to drive upon auto owners. In this section, we propose to analyze another potential remedy for LPR, which allows auto owners to trade these permits with each other. The rationale behind this idea is that buying another vehicle to gain access to driving may be inefficient compared to acquiring permits just enough to fulfill one's need. Hence, a trading scheme could facilitate more efficient

\footnotetext{
${ }^{7}$ These conditions may be derived from a UE traffic assignment model with a side constraint, see e.g. Larson and Patriksson (1995); Nie et al. (2004).
} 


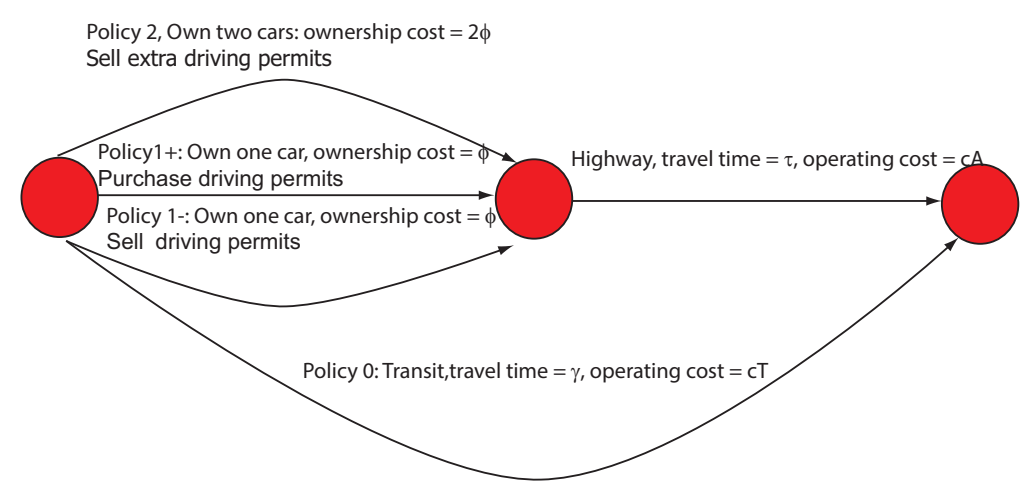

Figure 2: Network representation for license plate rationing with trading among auto owners

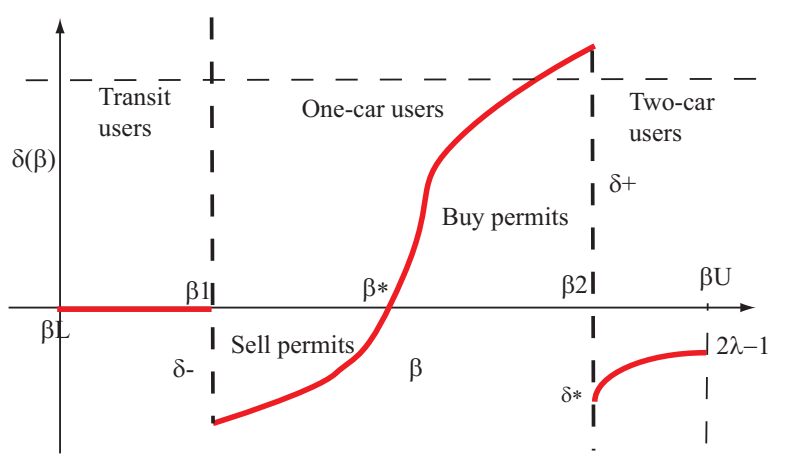

(a) General form

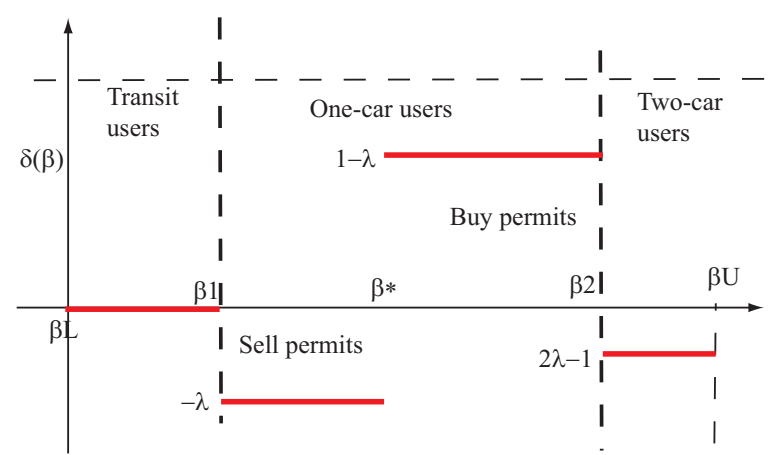

(b) Actual functional form

Figure 3: Permit trading function for LPR-TAO

allocation of permits among auto owners, and as a result help reduce the total system cost as well as auto ownership.

Since the permit is no longer tied to license plates (i.e., one can acquire additional permits other than what his/her license plate number is entitled to), this policy has to be implemented and enforced by other means. Each traveler may need to have an account that can receive virtual permits (maybe as an encrypted code) from the authority. This code can then be traded between travelers through a virtual market and linked to registered vehicles through an on-board unit (e.g. electronic license plates). For travelers, the trading and use of the permits can be done on a mobile device with very little efforts. For the authority, the enforcement can be completely automated through a vehicle-to-infrastructure (V2I) communication protocol, which is an on-going effort led by the US Department of Transportation (see http://www.its.dot.gov/vii/).

With this new scheme, dubbed LPR with Trading among Auto Owners (LPR-TAO), travelers face four choices: transit (0), own one car and sell some driving permit (1-), own one car and buy some driving permits (1+), and own two cars and sell the extra permits (2). Figure 2 represents each policy with a route in a simple network.

For a given LPR with $\lambda$, a traveler who owns at least one vehicle may purchase or sell a certain amount of permits, which is assumed to be a function of his/her value of time $\beta$, denoted as $\delta(\beta)$. Figure 3(a) illustrates roughly how this function may look like. The function will be referred to as the permit trading function hereafter. In the plot, $\delta_{+}$and $\delta_{-}$are the maximum number of permits bought and sold by one-car travelers, respectively, and $\delta^{*}$ is the maximum number of permits sold by two-car travelers.

Let $P$ be the price one has to pay to acquire permits if s/he must drive everyday but does not have any 
permits at the beginning. The cost corresponding to each policy $r \in R=\{0,1+, 1-, 2\}$ can be written as follows:

$$
\begin{aligned}
u_{1+}(\beta) & =(\lambda+\delta(\beta))\left(\beta \tau+c_{A}\right)+(1-\lambda-\delta(\beta))\left(\beta \gamma+c_{T}\right)+\phi+\delta(\beta) P \\
u_{1-}(\beta) & =(\lambda+\delta(\beta))\left(\beta \tau+c_{A}\right)+(1-\lambda-\delta(\beta))\left(\beta \gamma+c_{T}\right)+\phi+\delta(\beta) P \\
u_{2}(\beta) & =\beta \tau+c_{A}+2 \phi+P \delta(\beta) \\
u_{0}(\beta) & =\beta \gamma+c_{T}
\end{aligned}
$$

Let $f_{r}, r \in R$ be the number of travelers choosing the policy $r$, and define

$$
\beta^{*}=F^{-1}\left(f_{2}+f_{1+}\right), \beta_{1}=F^{-1}\left(f_{2}+f_{1}\right), \beta_{2}=F^{-1}\left(f_{2}\right) ; f_{1}=f_{1+}+f_{1-} .
$$

It is easy to see that

$$
\beta_{2} \geq \beta^{*} \geq \beta_{1} .
$$

To define the permit function $\delta(\beta)$ in greater details, the following result is needed.

Lemma 1. Consider two travelers $a$ and $b$ with permits $\lambda_{a}, \lambda_{b} \in(0,1)$ and VOTs of $\beta_{a}$ and $\beta_{b}$ such that $\beta_{a}>\beta_{b}$. Traveler a would always gain more than what traveler $b$ would lose if $\left.\epsilon \in\left(0, \min \left(\lambda_{b}, 1-\lambda_{a}\right)\right)\right)$ permits are transferred from $b$ to $a$.

Proof: By transferring $\epsilon$ permits, traveler $a$ would gain $y_{a}=\epsilon\left(\beta_{a}(\gamma-\tau(q))+c_{T}-c_{A}\right)$ and traveler $b$ would lose $y_{b}=\epsilon\left(\beta_{b}(\gamma-\tau(q))+c_{T}-c_{A}\right)$ (cf. Equations (10a) and (10b)). Because $\beta_{a}>\beta_{b}$ and $\gamma>\tau(q)$, it is easy to see that $y_{a}>y_{b}$.

Without loss of generality, suppose at $\lambda=1$, there are both one-car travelers and zero-car travelers ${ }^{8}$. Lemma 1 suggests that trading will always occur when $\lambda$ is restricted below 1. Also, since trading is mutually beneficial, the permit price must be positive, i.e., $P>0$. Thus, as $\lambda$ decreases from 1 , relatively rich onecar travelers will begin to buy permits from their relatively poor peers. As $\lambda$ becomes more restrictive, the permit will become more valuable, which may induce more zero-car travelers to become permit suppliers by acquiring an automobile. When very restrictive $\lambda$ drives the demand for permits sufficiently high, the richest travelers may begin to acquire the second automobile to increase the permit supply. The following result characterizes the permit trading function at user equilibrium. We note that the zero-car travelers neither have permits to sell nor have the incentive to buy them.

Proposition 1. If $\lambda \in[0.5,1]$ and $\beta_{1}<\beta^{*}<\beta_{2}<\beta_{U}$, then at user equilibrium, the permit trading function

$$
\delta(\beta)=\left\{\begin{array}{cc}
1-2 \lambda & \beta \in\left[\beta_{2}, \beta_{U}\right] \\
1-\lambda & \beta \in\left(\beta^{*}, \beta_{2}\right) \\
-\lambda & \beta \in\left[\beta_{1}, \beta^{*}\right)
\end{array}\right.
$$

Proof: First, since $\beta^{*}$ is the value of time at which one-car travelers switch from buying to selling, we have $\delta(\beta)>0$ for $\beta \in\left(\beta^{*}, \beta_{2}\right]$ and $\delta(\beta)<0$ for $\beta \in\left[\beta_{1}, \beta^{*}\right)$.

We first show $\delta(\beta)=1-\lambda$ for $\beta \in\left(\beta^{*}, \beta_{2}\right)$. Suppose a traveler $a$ with $\delta\left(\beta_{a}\right)<1-\lambda$ exists for $\beta_{a} \in\left[\beta^{*}, \beta_{2}\right)$. We claim that for all travelers such that $\beta \in\left[\beta_{1}, \beta^{*}\right), \delta(\beta)=-\lambda$, and for all travellers such that $\beta \in\left(\beta^{*}, \beta_{2}\right]$ and $\beta \neq \beta_{a}, \delta(\beta)=1-\lambda$. To see this, note that Lemma 1 asserts that otherwise traveler $a$ may have the incentive to trade with another traveler. Therefore, $\beta_{a}$ must equal $\beta^{*}$ because otherwise a $\beta_{b} \in\left(\beta^{*}, \beta_{a}\right)$ can be found with $\delta\left(\beta_{b}\right)=1-\lambda$, which again leads to a contradiction with the user

\footnotetext{
${ }^{8}$ At $\lambda=1$, no one would have the incentive to buy the second car per our assumptions.
} 
equilibrium requirement. We thus show that for any $\beta \in\left(\beta^{*}, \beta_{2}\right), \delta(\beta)=1-\lambda$. We note that $\delta\left(\beta^{*}\right)$ is indefinite because the discontinuity of the function at the point. We can show $\delta(\beta)=-\lambda$ for $\beta \in\left[\beta_{1}, \beta^{*}\right)$ similarly.

Second, that $\delta(\beta)$ must be smaller than or equal to $1-2 \lambda$ for $\beta \in\left[\beta_{2}, \beta_{U}\right]$ is obvious: when the sold permits are less than $|1-2 \lambda|$, selling more permits will always create positive return for individual travelers. We only need to show that no two-car traveler with $\beta>\beta_{2}$ has the incentive to sell more than $|1-2 \lambda|$. First, we note that if there are more than one such traveler with distinctive $\beta$, the system is not at equilibrium as per Lemma 1. If there is only one such traveler, its $\beta$ has to equal $\beta_{2}$ (otherwise it contradicts with the user equilibrium requirements). However, as per (1) above, one can find a traveler with $\beta \in\left(\beta^{*}, \beta_{2}\right)$ who has more permits than this traveler. Lemma 1 implies that trading will take place between the two travelers, hence the system is again not at the equilibrium. Since we hence rule out the possibility that two-car travelers would want to sell more or less than $|1-2 \lambda|, \delta(\beta)=1-2 \lambda$ for all $\delta \in\left[\beta_{2}, \beta_{U}\right]$.

Figure $3(\mathrm{~b})$ plots the actual trading function. It clearly shows that, contrary to the intuition, $\delta(\cdot)$ does not change smoothly with the value of time. Rather, the amount of permits traded jumps abruptly, and its change coincides with the change in the primary travel choices.

We proceed to analyze the user equilibrium solutions for $\lambda \in[0.5,1]$. At $\beta^{*}$, the traveler is indifferent in terms of permit trading. Specifically,

$$
u_{1+}\left(\beta^{*}\right)=u_{1-}\left(\beta^{*}\right) \rightarrow \beta^{*}(\tau(q)-\gamma)+\Delta c+P-\phi=0 .
$$

It is worth noting that the above equation holds regardless of the value of $\delta(\cdot)$ in Equations (10a) and (10b).

When $\lambda$ is sufficiently close to $1, f_{2}=0$ because the extra car adds little value for very minor driving restriction. In this case, the permit trading equilibrium requires

$$
f_{1+}(1-\lambda)=f_{1-} \lambda \rightarrow f_{1}=\frac{f_{1+}}{\lambda} .
$$

As $\lambda$ decreases from 1, more and more zero-travelers would buy cars because of the appeal of profiting from selling the credit. That is, $f_{1}$ will keep increasing as $\lambda$ decreases. However, as long as $f_{1}<d$, the equilibrium conditions require (noting Proposition 1)

$$
u_{1-}\left(\beta_{1}\right)=u_{0}\left(\beta_{1}\right) \rightarrow P=\frac{\phi}{\lambda} .
$$

Using this permit price and noting $f_{2}=0$, we can directly solve for $f_{1+}$ from Equation (11) (because $\beta^{*}=F^{-1}\left(f_{1+}\right)$ with $\left.f_{2}=0\right)$, and then $f_{1-}$ from Equation (12).

As some point, when $f_{1}$ reaches $d$ (i.e. all travelers become auto owners), the supply of permits by relatively poor one-car travelers can no longer keep up with the demand. In this case, the relatively rich travelers will begin to buy the second car and sell the extra permits $(2 \lambda-1)$. The equilibrium conditions require (noting Proposition 1)

$$
u_{1+}\left(\beta_{2}\right)=u_{2}\left(\beta_{2}\right) \rightarrow P=\frac{\phi}{\lambda} .
$$

Interestingly, the emerging two-car travelers would keep the permit price increasing with $\lambda$ at exactly the same trajectory as before.

Let $\hat{\lambda}$ be the value of $\lambda$ such that $f_{1}=d$. We can solve $\hat{\lambda}$ from Equation (11) after setting $f_{2}=0, f_{1+}=$ $d \lambda$ and $P=\phi / \lambda$. If $\hat{\lambda}<0.5$, it means for any $\lambda \in[0.5,1], f_{1}<d$, in which case the two-car owners would never emerge. If $\hat{\lambda}>0.5$, then for any $\lambda \in(0.5, \hat{\lambda})$, all travelers would own at least one car $d=f_{1}+f_{2}$, and some would buy the second car $f_{2}>0$. To summarize 
- When $\lambda \in[\max (0.5, \hat{\lambda}), 1)$, travelers may choose policy $0,1+$ or $1-$, but not 2 .

- When $\lambda \in[0.5, \max (0.5, \hat{\lambda})]$, travelers may choose policy $1+, 1-$ or 2 , but not 0 .

Finally, note that when $f_{2}=0, q=\lambda f_{1}$, and when $f_{2}>0, q=\lambda\left(2 f_{2}+f_{1}\right)$.

From the above analysis, we can see that enabling permit trading may initially motivate more travelers to own an automobile. Under an unfavorable setting (e.g. $\lambda \leq \hat{\lambda}$ ) every traveler would choose to own at least one vehicle. The reason is that associating the permit with auto ownership would encourage travelers to acquire the "entitlement". For those with low VOT, they would be better off by simply selling their entitled permits to others while primarily using transit to fulfill their travel needs. However, since the scheme could reduce the need for the second car, its impact on the overall auto ownership may be indefinite.

\section{Permit rationing and trading with all travelers}

Having explained in the previous section why LPR-TAO may fail, we now propose a slightly different policy that promises to fix the fundamental flaw in LPR-TAO: linking driving permit to auto ownership. Instead of giving permits only to those who own automobiles, the new policy would distribute all driving permits evenly among all travelers. For this reason, it will be referred to as Permit Rationing And Trading with All Travelers, or PRA-TAT. In this case, the control parameter that the authority needs to decide is the percentage of eligible travelers who will be allowed to drive. This parameter will also be denoted as $\lambda$, because it plays a similar role as the $\lambda$ in LPR. However, since $\lambda$ is no longer associated with licence plates, $\lambda$ is allowed to be lower than 0.5 in PRA-TAT.

PRA-TAT may be considered a hybrid of LPR and the tradable credit scheme (TCS) (e.g Yang and Wang, 2011; Nie, 2012): the way it distributes permits is similar to TCS (e.g. to all travelers, instead of just auto owners), whereas the permit use and enforcement is similar to LPR, i.e., it offers a simple and uniform access to the entire control area, rather than attempting to achieve system optimum using a dedicated facilityspecific credit collection scheme.

The analysis presented below will examine how permits trading leads to a stable equilibrium that corresponds to the control target of PRA-TAT, which is represented in our simple model as the "ideal" flow on the highway, denoted as $q_{0}$. For our purpose, let us assume that $q_{0}$ is exogenously determined, e.g. by solving a system optimal problem. Under PRA-TAT, purchasing an additional vehicle would not increase the traveler's accessibility to highway. Since there is no incentive to buy extra vehicles, that decision is excluded from the analysis. Consequently, only three policies are considered: use transit and sell permit to auto owners (0), own one car and sell portion of the permit to other car owners (1-), and own one-car and buy permits (1+). Let $\delta(\beta)$ be the amount of traded permits of one-car traveler, the costs associated with the three options are:

$$
\begin{aligned}
u_{1+}(\beta) & =(\lambda+\delta(\beta))\left(\beta \tau+c_{A}\right)+(1-\lambda-\delta(\beta))\left(\beta \gamma+c_{T}\right)+\phi+\delta(\beta) P \\
u_{1-}(\beta) & =(\lambda+\delta(\beta))\left(\beta \tau+c_{A}\right)+(1-\lambda-\delta(\beta))\left(\beta \gamma+c_{T}\right)+\phi+\delta(\beta) P \\
u_{0}(\beta) & =\beta \gamma+c_{T}-P \lambda
\end{aligned}
$$

Note that the transit users will always sell all the permits they have, as long as the price is positive, in order to minimize the cost.

Figure 4(a) gives a sketchy illustration of the permit trading function $\delta(\beta)$ in this case, where

$$
\beta_{1}=F^{-1}\left(f_{1+}+f_{1-}\right), \beta^{*}=F^{-1}\left(f_{1+}\right) .
$$




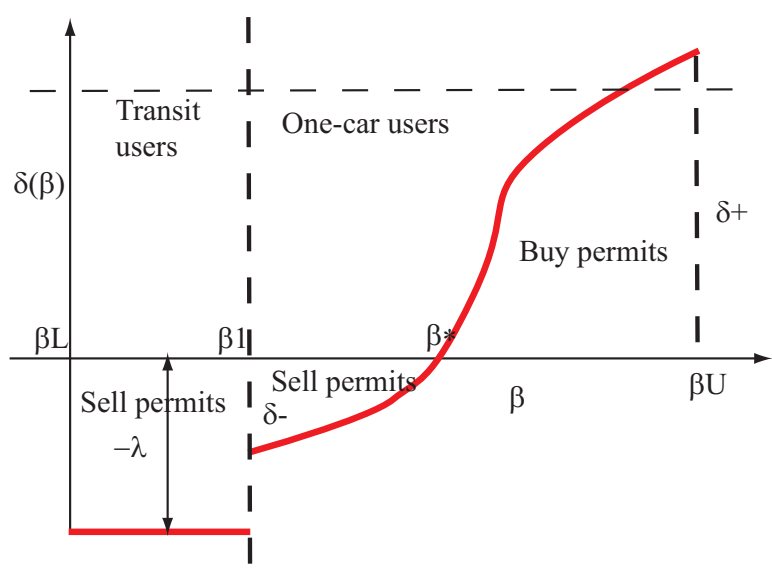

(a) General form

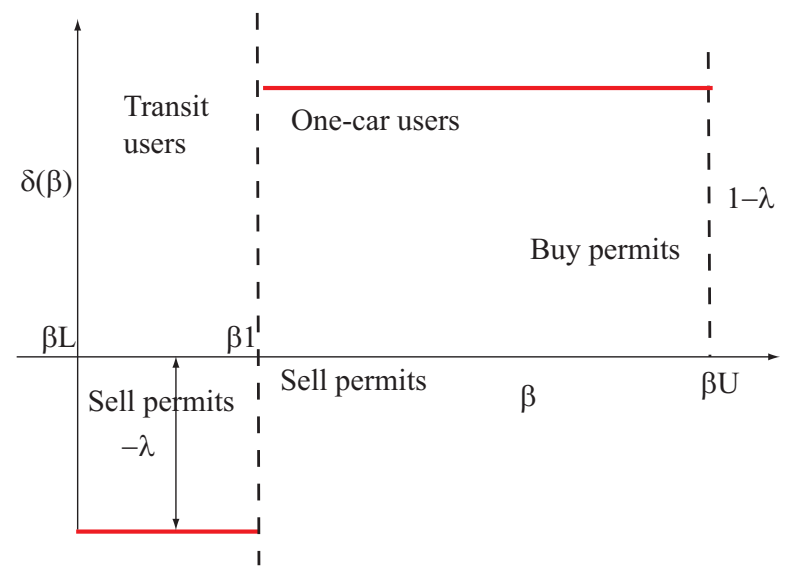

(b) Actual functional form

Figure 4: Permit trading function for PRA-TAT

Proposition 2. With the proposed PRA-TAT scheme, (1) no traveler would choose to own a car but sell permits at UE, i.e., $f_{1-}=0$. (2) one-car travelers must purchase $1-\lambda$ permit at UE, i.e.,

$$
\delta(\beta)=\left\{\begin{array}{cc}
1-\lambda & \beta \in\left[\beta_{1}, \beta_{U}\right] \\
-\lambda & \beta \in\left[\beta_{L}, \beta_{1}\right)
\end{array}\right.
$$

Proof: (1) Per Proposition 1, if $f_{1-}>0$, then $\delta(\beta)=-\lambda$ for all $\beta \in\left[\beta_{1}, \beta^{*}\right)$. This is no equilibrium since at least one traveler with $\left.\beta \in\left[\beta_{1}, \beta^{*}\right)\right]$ can reduce his/her cost by $\phi$ by selling the car. (2) can be proven similarly as in Proposition 1.

Proposition 2 shows that permit trading in PRA-TAT leads to a surprisingly simple equilibrium solution: transit users sell all permits $(\lambda)$ to auto owners, and auto owners purchase as much permits as needed to gain full access to the highway $(1-\lambda)$. Interestingly, the users' trading behavior is defined only by auto ownership, independent of the heterogeneity in the value of time.

Based on Proposition2, the permit trading equilibrium leads to

$$
f_{1}(1-\lambda)=\left(d-f_{1}\right) \lambda \rightarrow f_{1}=d \lambda
$$

Remember in this case, $f_{1}$ equals highway flow $q$. Therefore, if the authority wishes to achieve a target highway flow $q=q_{0}$, then it should give each traveler highway access permit in $\lambda=q_{0} / d$ days. For any given target flow $q_{0}$, the UE solution ( $P$ and $f_{1}$ ) may be solved by examining the following system equations

$$
\begin{gathered}
u_{1+}=u_{0} \rightarrow \beta_{1}\left(\tau\left(f_{1}\right)-\gamma\right)+\Delta c+P=0 \\
f_{1}=q_{0}
\end{gathered}
$$

\section{PRA-TAT and tradable credit scheme}

To understand the relationship between PRA-TAT and the tradable credit scheme (TCS), we now specify TCS in our setting. A system optimal (SO) TCS may be designed as follows. First, the optimal toll on the highway use, as defined in Equation (6), is replaced with a credit charge $\kappa=\mu_{s}$. Then, $K=p_{0} \kappa q_{s}$ credits are issued by the authority, where $p_{0}$ is a scalar. Finally, these credits are uniformly distributed among all travelers, who are allowed to trade the credits with each other. When the credit market clears, we must have

$$
\kappa q \leq K
$$


Following Yang and Wang (2011), we may construct the following optimization problem, from which the SO solution may be obtained.

$$
\min z(q)=\int_{0}^{q} F^{-1}(w) \tau(w) d w+\int_{q}^{d} F^{-1}(w) \gamma d w+\left(c_{A}+\phi\right) q+c_{T}(d-q)
$$

subject to:

$$
\kappa q \leq K, q \geq 0
$$

Let $p$ be the multiplier associated with the credit constraint. Ignoring the corner solution, the KKT conditions read

$$
\begin{array}{r}
F^{-1}(q) \tau(q)+p \kappa-\gamma F^{-1}(q)-\Delta c=0 ; \\
\kappa q=K=p_{0} \mu_{s} q_{s}
\end{array}
$$

It is easy to verify that $q=q_{s}, p=1 / p_{0}$ is a solution to the above equation system, by comparing it with (5). Also, note that

$$
\frac{d z(q)}{d q}=F^{-1}(q)(\tau(q)-\gamma)-\Delta c
$$

When $\tau(q)<\gamma$ (which is guaranteed in the neighborhood of an interior solution), $\frac{d z(q)}{d q}$ must be strictly increasing (note that $F^{-1}(q)$ is strictly decreasing and $\tau(q)$ is strictly increasing as per the assumptions). Consequently, $z(q)$ is strictly convex in the neighborhood of an interior solution. Since Problem (19) must hence admit an unique optimal solution, it follows that $q=q_{s}, p=1 / p_{0}$ must be the solution.

Therefore, the tradable credit scheme achieves exactly the same welfare result as applying an SO toll and then uniformly redistributing the toll revenue as a lump sum to all travelers. It also appears to achieve a similar outcome as PRA-TAT when $\lambda d=q_{s}$ in PRA-TAT. However, it is important to note that the construction of (19) is based on (20), which implicitly assumes that all auto owners, despite their heterogeneous value of time, would buy just enough credits to gain full access to driving. Given the inherent heterogeneity, it is not obvious why no auto owners would want to maintain only a partial access to driving and thereby pay a fraction of $\kappa$ or even sell some of their own endowment of credits (as portrayed in Figure 4(a)). This issue is fully resolved in Section 5 through the analysis of the trading function in Proposition 2.

\section{Numerical results}

In this section we present and discuss the results of numerical experiments designed to demonstrate the analytical results given in the previous sections. We first describe the experiment setting in what follows.

\subsection{Experiment setting}

Following Nie (2016), the relationship between highway travel time and the highway flow $q$ is represented using a BPR function

$$
\tau(q)=\tau_{0}\left(1+0.15\left(\frac{q}{C}\right)^{4}\right)
$$

and the VOT distribution is depicted using a first-order rational function

$$
F(\beta)=\frac{d\left(\beta_{U}-\beta\right)}{\rho \beta+\beta_{U}} .
$$


Table 1: Description of model parameters

\begin{tabular}{r|r|r|l}
\hline Parameters & Default value & Unit & Description \\
\hline$\gamma$ & 1 & hour & Transit travel time/trip \\
$c_{T}$ & 5 & $\$$ & Transit-specific user cost/trip \\
$\tau_{0}$ & 0.5 & hour & Highway free flow travel time/trip \\
$C$ & 500 & veh/hour & Highway capacity \\
$d$ & 1000 & person & Total demand \\
$c_{A}$ & 6 & $\$$ & Auto-specific user cost/trip \\
$\phi$ & 5 & $\$$ & Auto capital cost/trip \\
$\beta_{U}$ & 60 & $\$ /$ hour & Highest VOT \\
$\rho$ & 0.1 & - & Index of wealth \\
\hline
\end{tabular}

Note: the road capacity and demand are made up so that the equilibrium flow distribution falls into a reasonable range, i.e., not too close to corner solutions. The mode-specific parameters (such as travel time and user costs) are estimated based on the commute trips between Downtown Chicago and its north suburbs.

In Equation (22), $\tau_{0}$ is the free flow travel time, and in Equation (23), $\rho>-1$ is interpreted as an index of wealth: $\rho=0$ represents a population with a uniformly distributed VOT, and $\rho \in(-1,0)(\rho>1)$ represents a population with a higher percentage of rich (poor) people (Nie, 2016). Table 1 lists the default values of all input parameters used in the experiment (same as in Nie (2016)).

To test the sensitivity of the results to key parameters, the numerical experiments include the following five scenarios:

Scenario D All parameters take the default value in Table 1.

Scenario $\mathbf{P}$ All parameters take the value in Table 1, except $\rho=4$. This corresponds to a case of poor population.

Scenario R All parameters take the value in Table 1, except $\rho=-0.6$. This corresponds to a case of rich population.

Scenario $\mathbf{L}$ All parameters take the value in Table 1, except $\phi=2.5$. This corresponds to a case of low auto capital cost.

Scenario H All parameters take the value in Table 1, except $\phi=10$. This corresponds to a case of high auto capital cost.

\subsection{LPR-NVQ policy}

Figure 5 reports the UE solutions under three LPR-NVQ policies, corresponding to $K_{0}=1.0,1.2$ and 1.5. Recall that $K_{0}$ is the ratio between the target number of automobiles and the UE highway flow at $\lambda=1$. Figure 5-(a) shows that each policy effectively restricts the total number of automobiles at the level dictated by $K_{0}$. For $K_{0}=1.0$, for example, the total number of automobiles remains unchanged when $\lambda$ decreases from 1 to 0.5. From Figure 5-(b) and (d) we can see that the NVQ policy is quite effective in promoting transit use and reducing highway congestion. For sufficiently small $\lambda$, the number of zero-car travelers under some NVQ policies actually exceeds the system optimal (SO) solution. It is not difficult to see why this is the case: when NVQ is implemented with LPR, the travelers are left with no viable options but transit. 


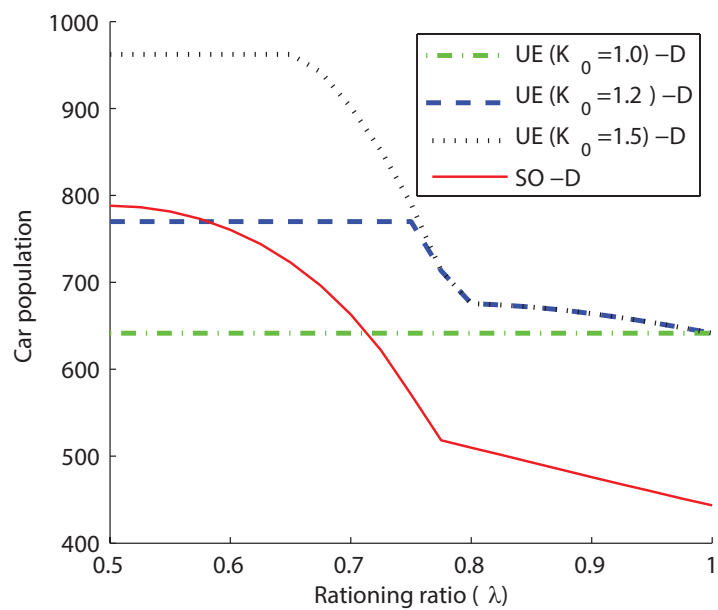

(a)

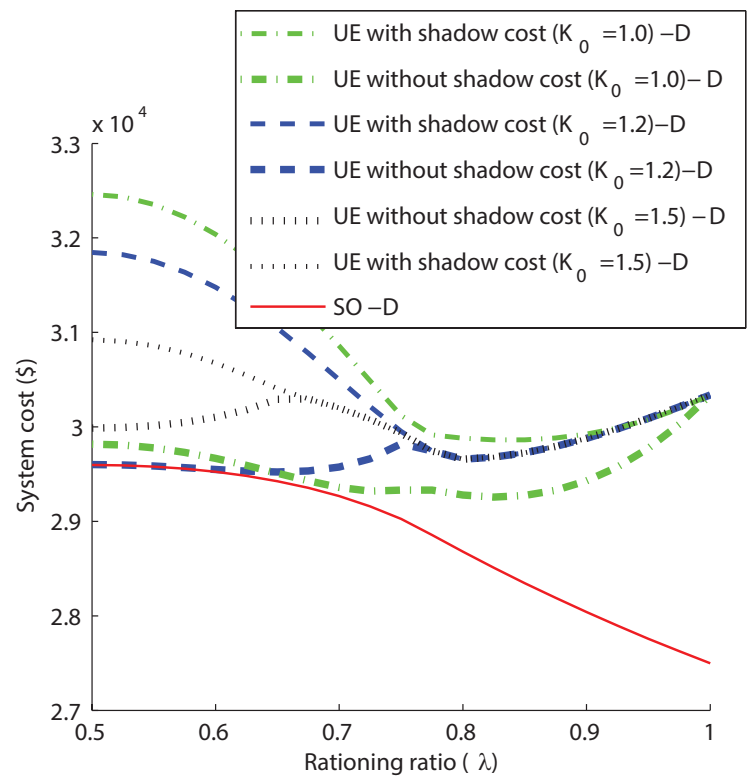

(c)

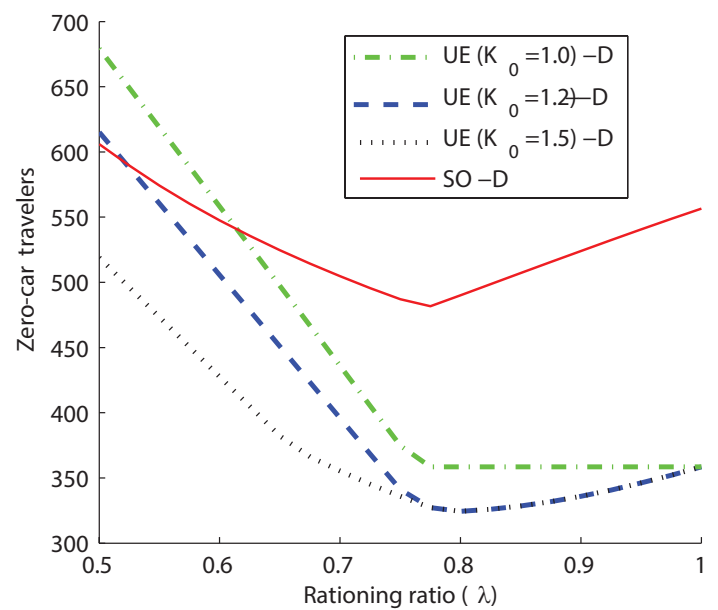

(b)

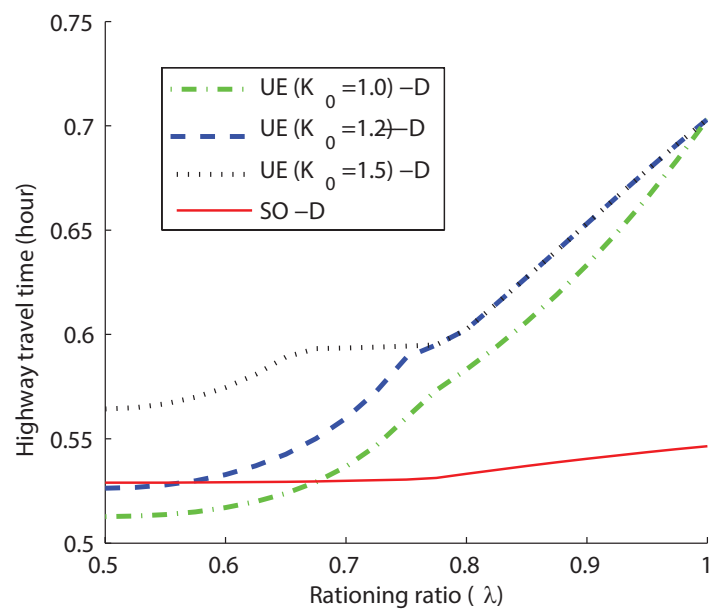

(d)

Figure 5: UE solutions under three NVQ policies $\left(K_{0}=1.0,1.2,1.5\right)$ 

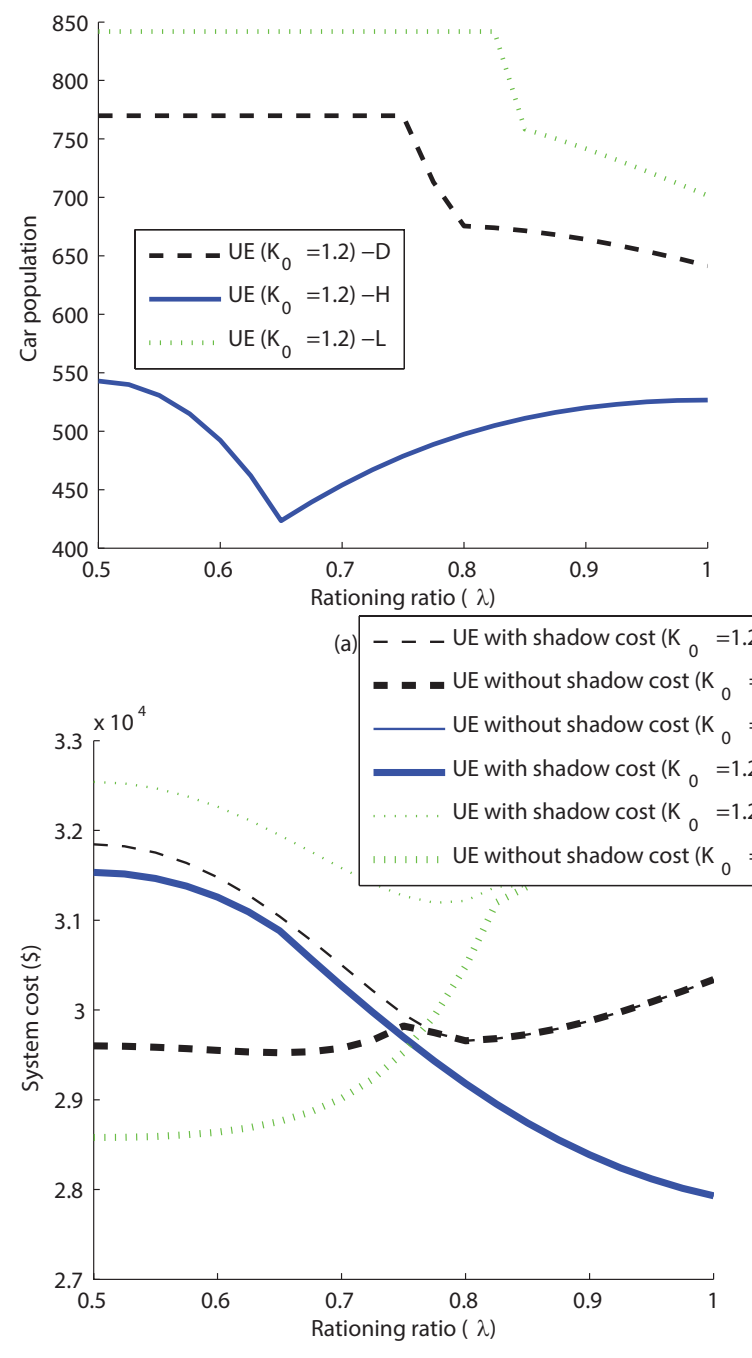

(c)

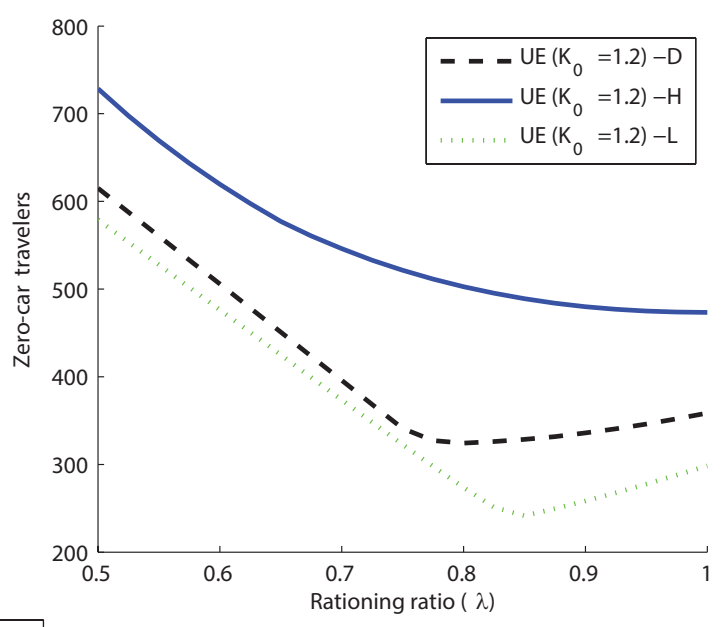

(b)

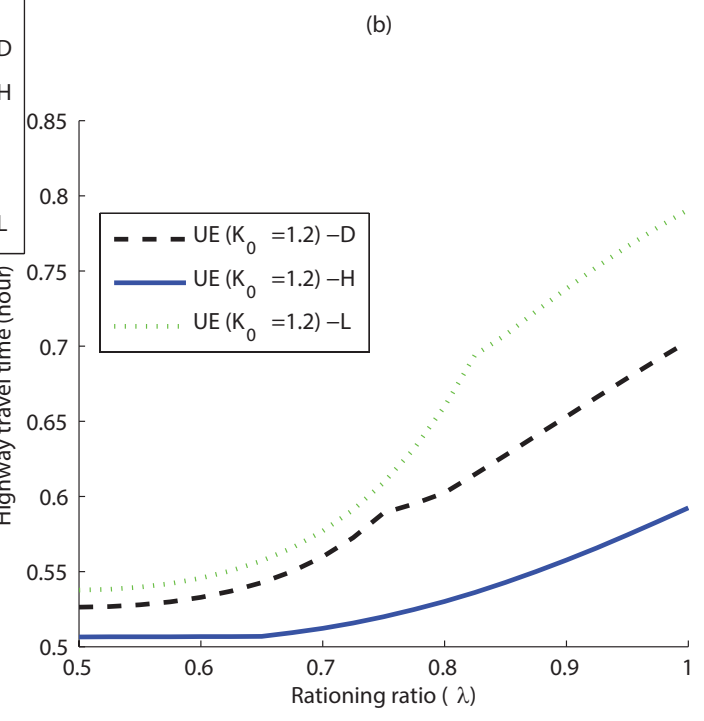

(d)

Figure 6: Sensitivity of NVQ policy to the auto capital cost $\phi\left(K_{0}=1.2\right)$

Figure 5-(c) compares the system costs under the NVQ policies with the SO cost. Note that for each NVQ policy we consider the cost with or without the shadow cost, which is the cost imposed on each traveler by the NVQ policy through Constraint (8). The shadow cost is measured by the multiplier $\nu$. When the shadow cost is excluded, the NVQ policies perform rather well. For $K_{0}=1.0$ and $K_{0}=1.2$, they always outperform the benchmark UE cost (the convergent point of the cost curves on the right end), and when $\lambda$ is small, their costs are comparable to the SO cost. Also, in general, the tighter the NVQ policy is, the more improvement it generates.

The picture in Figure 5-(c) becomes very different when the shadow cost is accounted for. With the shadow cost, the system costs given by the NVQ policies are often higher than the benchmark UE cost. In addition, the more restrictive NVQ policies in this case often lead to worse performance due to the higher shadow price. Consequently, the effectiveness of the LPR-NVQ policies is questionable with shadow costs.

Figure 6 compares the solution of one NVQ policy $\left(K_{0}=1.2\right)$ in three scenarios $(\mathrm{D}, \mathrm{H}, \mathrm{L})$ to examine the sensitivity of the policy to the auto capital cost. Most results here match the expectation perfectly: the higher auto capital cost leads to lower auto ownership (Figure 6-(a)), more travelers without cars (Figure 

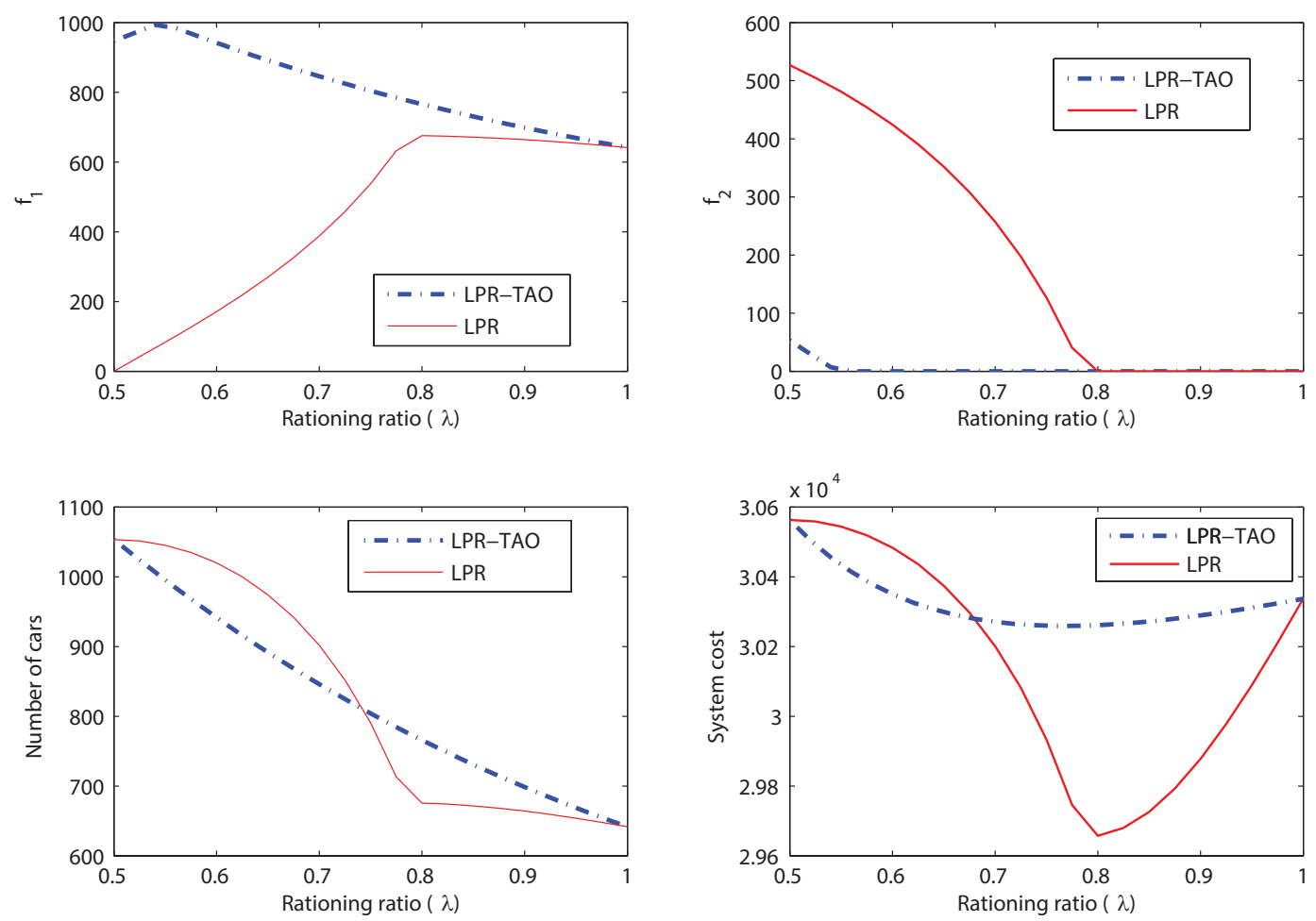

Figure 7: Comparison of LPR and LPR-TAO in Scenario-D

6-(b)) and lower highway travel time (Figure 6-(d)). In Scenario-H, the system cost always gets worse when LPR is implemented. The NVQ policy never takes effect because the auto capital cost is already high enough to discourage travelers from purchasing additional vehicles. This can be seen from the fact that the cost curves with and without shadow costs completely overlap. In Scenario-L, because purchasing new vehicles is cheap, the NVQ policy results in high shadow price which can be seen from the large vertical distance between the two cost curves. Finally, it is worth noting that the cost curve of Scenario-H is always lower than that of Scenario-L and Scenario-D (with shadow costs), despite automobiles being more expensive to acquire in the former. This finding suggests that simply increasing the cost of auto ownership may lead to meaningful welfare improvements under LPR.

\subsection{LPR-TAO policy}

Figure 7 compares the UE solutions obtained under LPR and LPR-TAO in Scenario-D. The results confirm that enabling trading induces more travelers to buy their first automobile: almost all travelers would own a car when $\lambda$ is reduced to about 0.55 under LPR-TAO, whereas the number of one-car travelers is close to zero under LPR at the same value of $\lambda$. On the other hand, LPR-TAO does effectively reduce the demand for the second car, as expected. Overall, LPR-TAO would significantly increase the total number of cars for less restrictive $\lambda$, although the two policies yield almost the same number of total cars when $\lambda$ is close to 0.5. LPR-TAO also leads to a higher system cost than LPR for modest levels of restrictions. However, it does outperform LPR when the value of $\lambda$ is close to 0.5 .

Figure 8 reports detailed UE flow solutions in Scenarios D, R and P. The plots reveal, as expected from the analysis, the number of one-car travelers who sell (buy) credits steadily increases (decreases) in all scenarios as $\lambda$ decreases from 1 . The differences between the plots in the three scenarios also match 

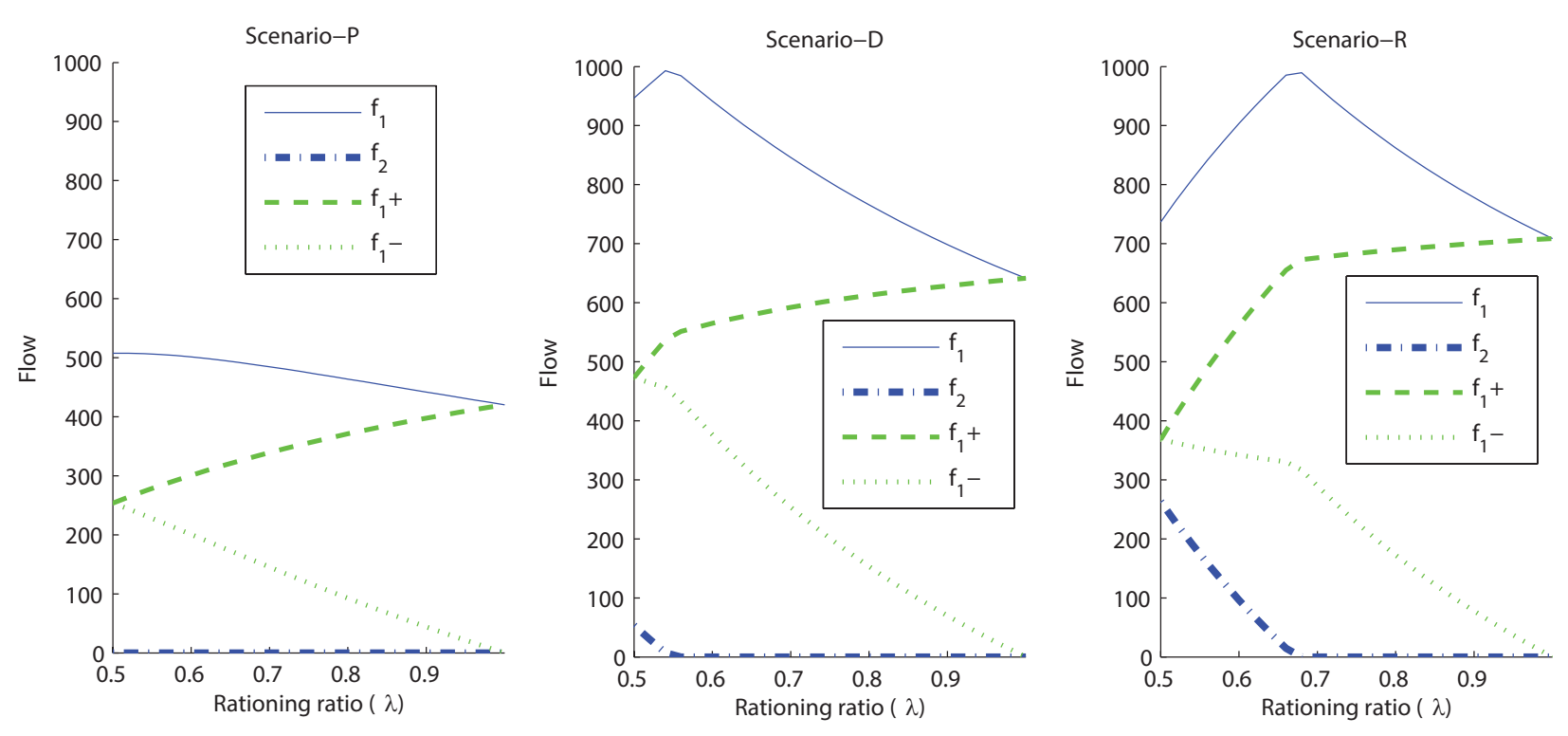

Figure 8: UE flow solution under LPR-TAO in Scenarios D, R and P

the expectation. For the richer population (Scenario-R), the increase in the car ownership is sharper and for restrictive $\lambda$, there are more travelers who own two cars. For the poorer population (Scenario-P), the number of car owners is much lower: only half of the population owns one car, and nobody owns two cars, even when $\lambda=0.5$.

Figures 9-(a) and (b) confirm that a lower auto capital cost (Scenario-L) leads to a higher auto ownership, and vice versa. In fact, a sufficiently high auto capital cost may cause the auto ownership to drop as the restriction gets tighter (see Figure 9-(a)). Figure 9-(c) shows that the low auto capital cost helps to bring down the total system cost, especially for more restrictive $\lambda$. Clearly, in such cases, forcing travelers to use transit is more costly than allowing them to avoid the restriction by buying the second car. Figure 9-(d) confirms that the higher auto capital cost reduces the level of congestion, albeit such benefits are not enough to offset the loss caused by higher ownership costs.

Figure 10-(a) shows that the permit price varies with $\lambda$ as predicted by the analytical results. In all three scenarios $(\mathrm{D}, \mathrm{H}$, and $\mathrm{L})$, the price at equilibrium starts from $\phi($ at $\lambda=1)$, and increases on the curve of $\phi / \lambda$. Scenario-L has the highest trading volume in the three scenarios until $\lambda$ is reduced to about 0.65 , when onecar travelers begin to acquire the second car (hence reduce the demand for permits). Similarly, the trading volume in Scenario-D peaks around 0.55, which corresponds to the point where $f_{2}$ starts to increase from zero (see Figure 8).

\subsection{PRA-TAT policy}

To examine the effects of PRA-TAT, we consider a range of target flows $q_{0} \in\left[q_{s}, q_{e}\right]$ where $q_{e}$ and $q_{s}$ are the UE and SO highway flows, respectively. We note that the rationing ratio $\lambda$ (the $x$ axis in Figure 11 ) is computed as $q_{0} / d$. Figure 11-(a) shows that the number of cars matches perfectly with the target flow $q_{0}$, because Proposition 2 asserts that all auto owners must have full access to driving at equilibrium under PRA-TAT. Figures 11-(b) and (d) confirm that the travel time and system cost all converge to the corresponding values at $\mathrm{SO}$, when the control target moves from $q_{e}$ to $q_{s}$. Last but not least, Figure 11-(c) shows that, as $q_{0}$ decreases, the permit prices increases linearly until it matches the SO toll at $q_{o}=q_{s}$. Thus, PRA-TAT with an optimal $q_{0}$ can be a first-best policy in this simple case. While the above observations are 
(a)

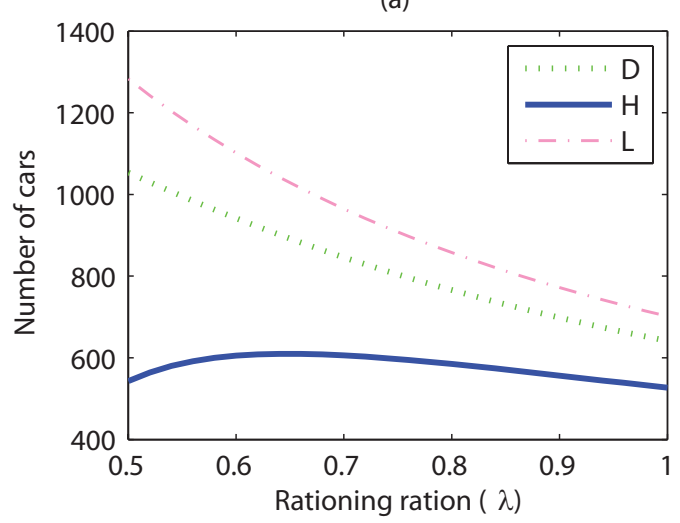

(c)

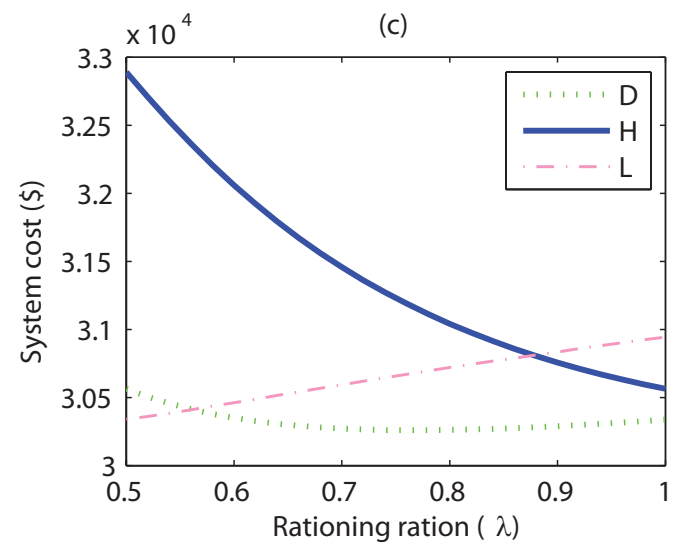

(b)

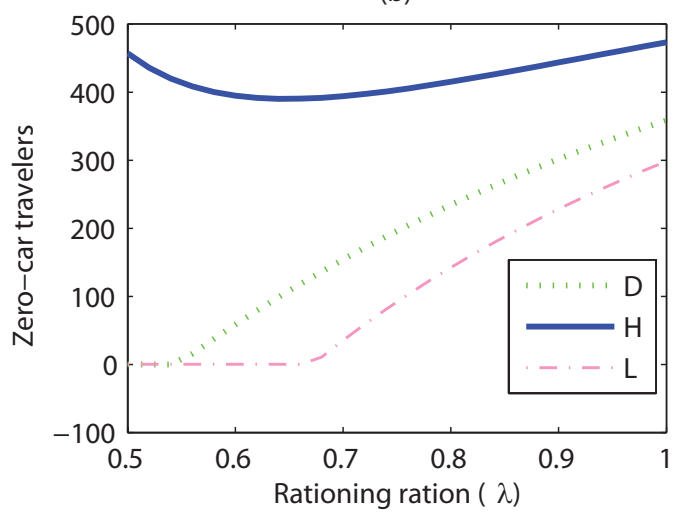

(d)

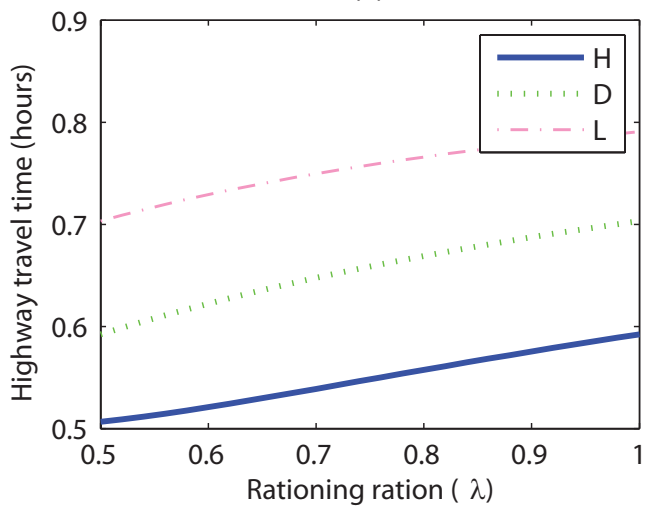

Figure 9: UE solutions under LPR-TAO in Scenarios D, H and L
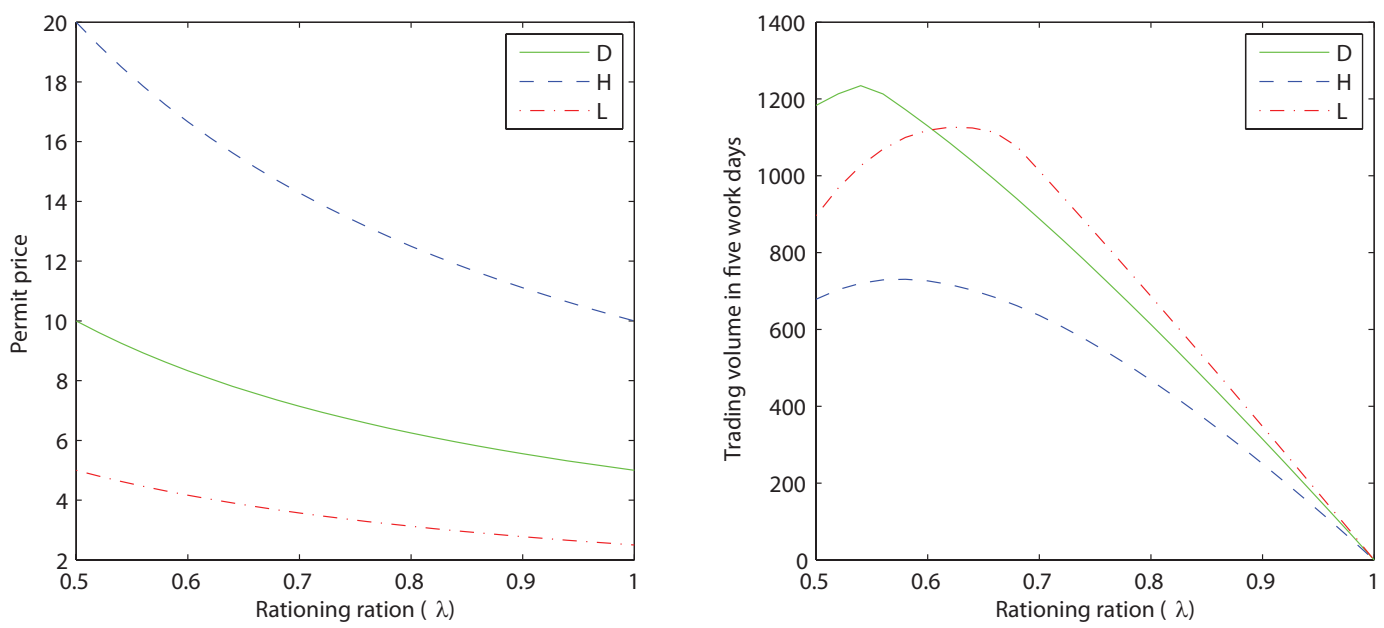

Figure 10: Permit price and trading volume under LPR-TAO in Scenarios D, H, L 
(a)

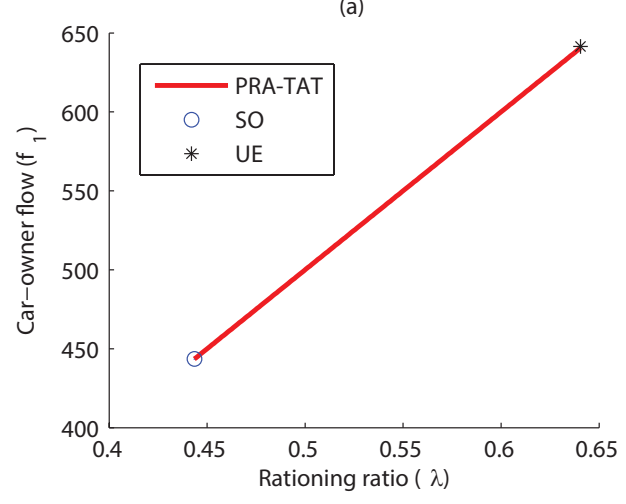

(c)

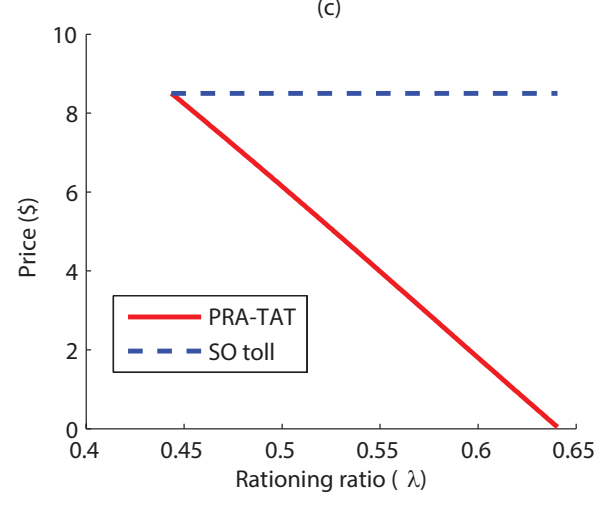

(b)

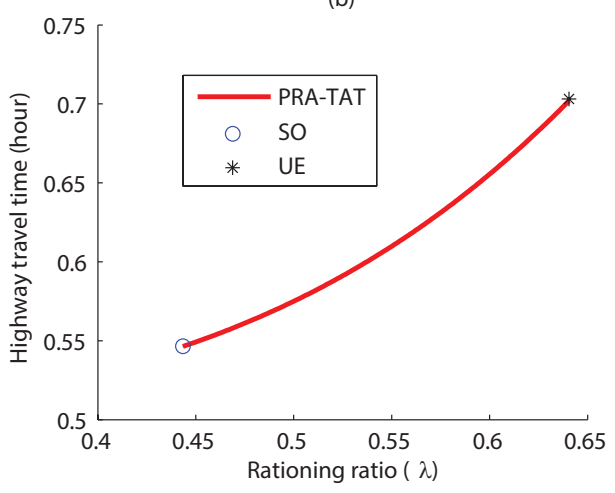

(d)

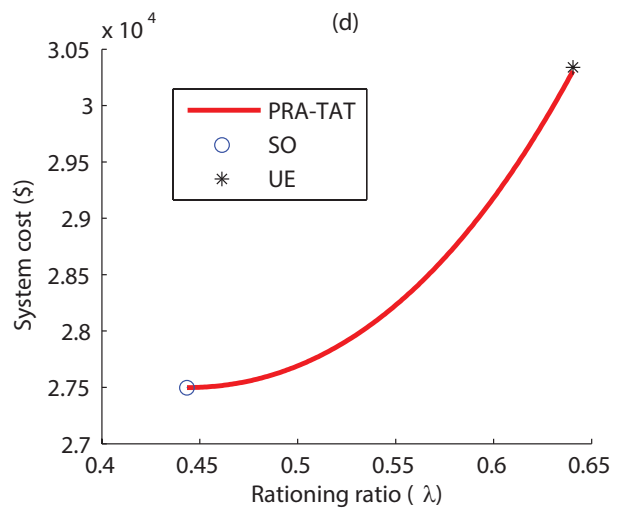

Figure 11: UE solution under PRA-TAT in Scenario-D

quite promising, we caution that PRA-TAT is meant to be a replacement for LPR that is by design "coarse", easy-to-implement, and reasonably effective. In real world, its performance is most likely second-best.

Figure 12 compares the welfare effects of PRA-TAT and LPR-TAO in three scenarios: D, P and R. In each contour plot, the $x$-axis represents VOT $\beta$ and the $y$-axis represents the target flow $q_{0}$ (for PRA-TAT) or $\lambda$ (for LPR-TAO). The color in the plot represents the difference between the UE costs of a traveler (identified by $\beta$ ) before and after a demand management policy (identified by $q_{0}$ or $\lambda$ ) is implemented. The lighter color represents greater cost increase associated with the policy. Roughly speaking, therefore, the dark areas are where travelers benefit from a policy. Note that the coloring scale varies across different plots.

Figure 12-(c) shows that in Scenario-D, LPR-TAO mostly benefits the travelers with high value of time at the expense of those with medium value of time. Specifically, the permit-buying travelers with low value of time suffer the largest loss. Those who choose not to drive (including the travellers who do not own cars and the travelers who own a car but sell all the permits), located at the left side on the plot, are not affected by the policy at all ${ }^{9}$. The regressiveness of the policy generally becomes worse when the driving restriction is tighter. For a richer population (Figure 12-(e)), the pattern of regressive welfare effects is similar but the maximum welfare loss tends to be lower. Figure 12-(a) shows that no one is better off with LPR-TAO when it is implemented for a poor population.

The welfare effects of PRA-TAT is quite different. All travelers are better off under PRA-TAT in Scenario-D, as seen in Figure 12-(d). Because they are compensated from selling permits, transit users are always better off and the benefit increases as the restriction becomes tighter (smaller $q_{0}$ ). Clearly, the auto owners with low value of time are those who benefit the least, because they cannot gain much from the

\footnotetext{
${ }^{9}$ This is true because the travel cost on transit is always constant.
} 
(a) LPR-TAO, Scenario-P
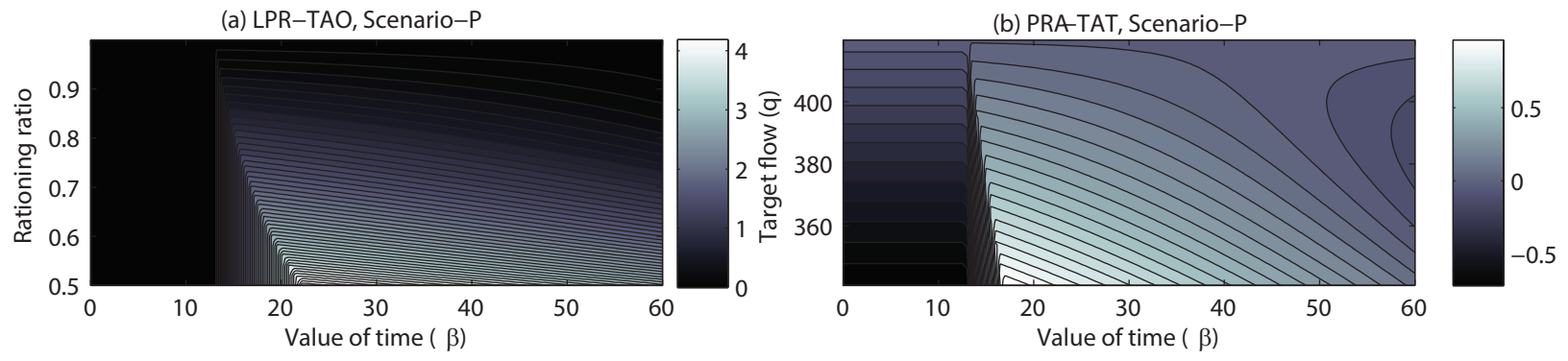

(c) LPR-TAO, Scenario-D

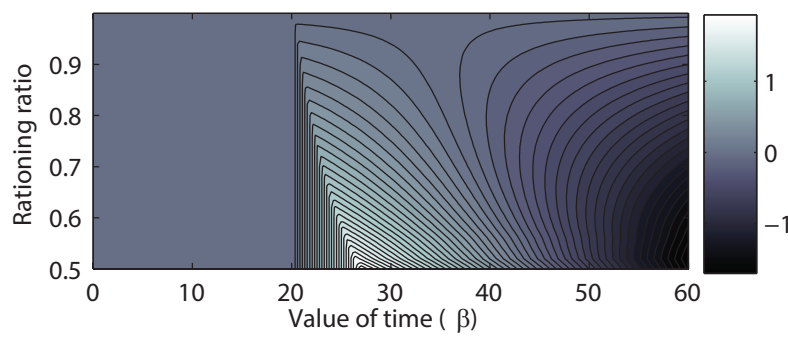

(d) PRA-TAT, Scenario-D

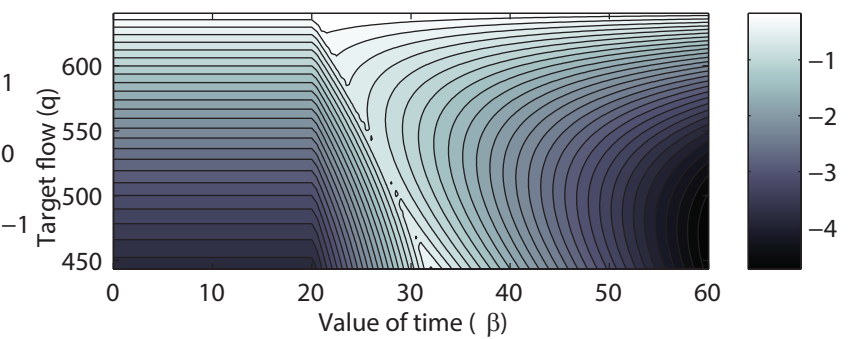

(e) LPR-TAO, Scenario-R
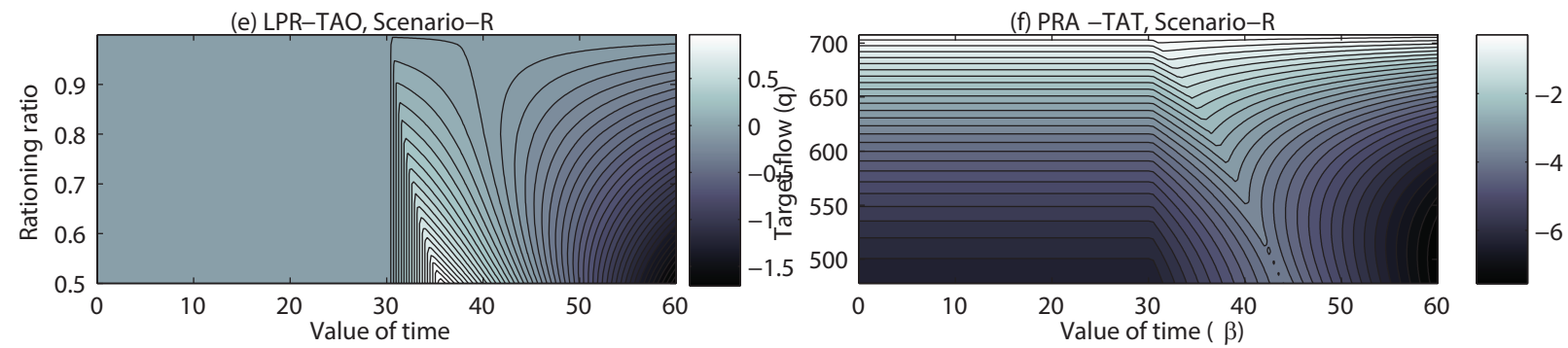

Figure 12: Welfare effects of LPR-TAO and PRA-TAT (compared to the total cost at UE when $\lambda=1$ ) 
congestion relief ${ }^{10}$. Another observation is that lowering the control target does not always reduce the cost for all auto owners, even though it does reduce the total cost. Welfare effects of PRA-TAT in Scenario-R (Figure 12-(f)) are very similar to those in Scenario-D, although the policy clearly generates more savings for the richer and poorer travelers (at the expense of the middle class). Finally, for a poorer population (Scenario-P), PRA-TAT is unable to achieve a Pareto improvement as it does in the other two scenarios ${ }^{11}$. The policy in this scenario tends to over-compensate transit users (who are always better off) at the expense of auto owners. In this case, most auto owners are worse off, and again, those with lower value of time are hurt more.

\section{Conclusions}

We have studied three new TDM policies designed to correct the shortcomings of license plate rationing (LPR). These policies either combine LPR with direct auto ownership control (LPR-NVQ), or turn the permit to use the road into a tradable commodity (LPR-TAO and PRA-TAT). They may be viewed as "derivatives" of LPR because they share some key features: simplicity (i.e, few and straightforward control targets) and revenue neutrality. Using a conceptual model that considers two modes (transit and driving) and user heterogeneity, the user equilibrium solutions under each new policy are analyzed. To model the policies based on permit trading, a function that links individuals' trading behavior to the value of time is introduced and analytically characterized.

The main findings from the numerical experiments are summarized as follows:

- If the new vehicle quota is able to keep the auto ownership at a proper level, LPR-NVQ is quite effective in improving "nominal" social welfare. However, direct control on auto ownership creates a shadow cost for travelers who would benefit from owning the second car but could not do so because of NVQ. When the shadow price is accounted for, social welfare under LPR-NVQ is no better than that under LPR alone.

- Allowing auto owners to trade their permit to drive (LPR-TAO) turns out to be a worse policy than LPR for relatively modest driving restrictions. In such cases, it encourages (rather than discourages) travelers to buy automobiles because the entitlement of driving, hence the profit from selling the permits, comes with auto ownership. As a result, the policy has little positive effects on the social welfare.

- Giving tradable permits to all travelers instead of just auto owners (PRA-TAT) seems a modest change to LPR-TAO, but it does dramatically change the welfare effects. Under PRA-TAT, travelers who decide to own private automobiles will acquire enough permits from those who do not so that the former can drive without restriction. Consequently, the permit each traveler should receive can be easily determined from the ratio between a desired highway flow level and the total demand. Importantly, when the desired flow level equals the system optimal flow, PRA-TAT becomes a revenue-neutral first-best policy for the simple analytical model.

\footnotetext{
${ }^{10}$ Similar findings have been reported in the literature. For example, Verhoef and Small (2004) showed that second-best pricing hurts users with intermediate VOT - those who are wealthy enough to own a vehicle but do not have much to gain from congestion relief.

${ }^{11}$ Nie and Liu (2010) showed that a Pareto-improving travel demand management exists if the value of time distribution $F(\cdot)$ is a concave function. We note that only when $\rho \leq 0$ (Scenario R), is the rational function (23) concave. Here, Scenario-P represents a case where that existence condition for Pareto-improving is not met.
} 
The above findings suggest that PRA-TAT is more efficient than other alternatives examined here. This policy may be introduced as an amendment in cities where LPR is already in place. Residents in these cities should find the policy easier to accept, because trading would expand their options, and potentially fulfil their travel needs at a lower cost. As explained before, we believe that implementing necessary trading and enforcement schemes is technically feasible now and will become more affordable in the near future.

It is worth emphasizing that our findings rely on several simplifying assumptions, of which the most significant include (1) the demand is fixed, (2) complex travel choices are reduced to the choice of three modes (transit, driving, or a mix of transit and driving), and (3) transit always provides a flow-independent, cheap and slow option compared to driving. Further research is needed to determine to what extent these assumptions would impact the performance of the policies considered in this paper. Validating the analytical results about the trading mechanism with more sophisticated tools (such as day-to-day dynamics or agentbased simulation models) constitutes another potential direction for further research.

\section{Acknowledgement}

The work was partially supported by National Science Foundation under the award number CMMI-1256021. The author wishes to thank two anonymous reviewers for their constructive comments on an earlier draft of the paper.

\section{References}

Arnott, R., de Palma, A., Lindsey, R., 1994. The welfare effects of congestion tolls with heterogeneous commuters. Journal of Transport Economics and Policy 28 (2), 139-161.

Beckmann, M., McGuire, C. B., Winsten, C. B., 1956. Studies in the Economics of Transportation. Yale University Press, New Haven, Connecticut.

CA, 2007. License plate rationing evaluation. Technical memorandum, Cambridge Systematics, prepared for New York City Department of Transportation.

URL https://www.dot.ny.gov/programs/repository/Tech Memo on License Plate Rationing.pdf

Chin, A., Smith, P., 1997. Automobile ownership and government policy: The economics of singapore's vehicle quota scheme. Transportation Research Part A 31 (2), 129-140.

Davis, L. W., 2008. The effect of driving restrictions on air quality in mexico city. Journal of Political Economy 116 (1), 38-81.

de Palma, A., Lindsey, R., 2011. Traffic congestion pricing methodologies and technologies. Transportation Research Part C 19 (6), 13771399.

DOE, 2014. Transportation energy data book. Technical report, US Department of Energy, http://cta.ornl.gov/data/download33.shtml.

Eskeland, G. S., Feyzioglu, T., 1997. Rationing can backfire: the day without a car in mexico city. The World Bank Economic Review 11 (3), 383-408.

Evans, A. W., 1992. Road congestion pricing: when is it a good policy? Journal of Transport Economics and Policy 26 (3), 213-244. 
Ferguson, E., 2000. Travel demand management and public policy. Aldershot, Hants, England.

Gärling, T., Eek, D., Loukopoulos, P., Fujii, S., Johansson-Stenman, O., Kitamura, R., Pendyala, R., Vilhelmson, B., 2002. A conceptual analysis of the impact of travel demand management on private car use. Transport Policy 9 (1), 59-70.

GUETA, G. P., GUETA, L. B., 2013. How travel pattern changes after number coding scheme as a travel demand management measure was implemented? Journal of the Eastern Asia Society for Transportation Studies 10 (0), 412-426.

Hau, T., 1992. Economic fundamentals of road pricing: A diagrammatic analysis. World Bank Policy Research Working Paper Series WPS 1070, The World Bank, Washington D.C.

Hau, T. D., 1990. Electronic road pricing: developments in hong kong 1983-1989. Journal of Transport Economics and Policy, 203-214.

Hau, T. D., 1998. Road Pricing, Traffic Congestion and the Environment. Edward Elgar, Cheltenham, UK, Ch. Congestion Pricing and Road Investment, pp. 39-78.

Larson, T., Patriksson, M., 1995. An augmented lagrangian dual algorithm for link capacity side constrained traffic assignment problems. Transportation Research Part B 29, 433455.

Lindsey, C. R., van den Berg, V. A., Verhoef, E. T., 2012. Step tolling with bottleneck queuing congestion. Journal of Urban Economics 72 (1), 46-59.

Nie, Y., 2012. Transaction costs and tradable mobility credits. Transportation Research Part B 46 (1), 189203.

Nie, Y., 2013. A new tradable credit scheme for the morning commute problem. Networks and Spatial Economics, Available at http://dx.doi.org/10.1007/s11067-013-9192-8.

Nie, Y., Liu, Y., 2010. Existence of self-financing and pareto-improving congestion pricing: Impact of value of time distribution. Transportation Research Part A 44 (1), 39-51.

Nie, Y., Zhang, H. M., Lee, D.-H., 2004. Models and algorithms for the traffic assignment problem with link capacity constraints. Transportation Research Part B, 38, 285-312.

Nie, Y. M., 2016. Why is license plate rationing not a good transport policy? Transportmetrica A On-line first (DOI: 10.1080/23249935.2016.1202354).

Nie, Y. M., Yin, Y., 2013. Managing rush hour travel choices with tradable credit scheme. Transportation Research Part B 50, 1-19.

Schrank, D., Lomax, T., Turner, S., 2012. 2012 urban mobility report. Texas Transportation Institute, Available online: http://tti. tamu. edu/documents/mobility_report_2010. pdf.

Small, K., Verhoef, E., 2007. The Economics of Urban Transportation. Routledge, UK.

Taylor, B., Kalauskas, R., 2010. Addressing equity in political debates over road pricing. Journal of Transportation Research Board 2187, 44-52.

Tsekeris, T., Vos, S., 2009. Design and evaluation of road pricing: state-of-the-art and methodological advances. Netnomics 10 (1), 5-52. 
Verhoef, E., Nijkamp, P., Rietveld, P., 1997. Tradable permits: their potential in the regulation of road transport externalities. Environment and Planning B 24 (4), 527-548.

Verhoef, E. T., Small, K. A., 2004. Product differentiation on roads. Journal of Transport Economics and Policy (JTEP) 38 (1), 127-156.

Vickrey, W. S., 1969. Congestion theory and transport investment. The American Economic Review 59 (2), 251-260.

Viegas, J., 2001. Making urban road pricing acceptable and effective: searching for quality and equity in urban mobility. Transport Policy 8 (4), 289294.

Wang, R., 2010. Shaping urban transport policies in china: Will copying foreign policies work? Transport Policy 17 (3), 147-152.

Wang, X., Yang, H., 2012. Bisection-based trial-and-error implementation of marginal cost pricing and tradable credit scheme. Transportation Research Part B 46 (9), 1085-1096.

Wang, X., Yang, H., Han, D., 2010. Traffic rationing and short-term and long-term equilibrium. Transportation Research Board 2196, 131-141.

Wardrop, J. G., 1952. Some theoretical aspects of road traffic research. Proceedings of the Institution of Civil Engineers, Part II 1, 325-378.

Xiao, F., Qian, Z. S., Zhang, H. M., 2013. Managing bottleneck congestion with tradable credits. Transportation Research Part B 56, 1-14.

Yang, H., Huang, H.-J., 2004. The multi-class, multi-criteria traffic network equilibrium and systems optimum problem. Transportation Research Part B 38 (1), 1-15.

Yang, H., Wang, X., 2011. Managing network mobility with tradable credits. Transportation Research Part B 45 (3), 580-594.

Ye, H., Yang, H., 2013. Continuous price and flow dynamics of tradable mobility credits. Transportation Research Part B 57, 436-450.

Zhu, S., Du, L., Zhang, L., 2013. Rationing and pricing strategies for congestion mitigation: Behavioral theory, econometric model, and application in beijing. Transportation Research Part B 57, 210-224.

Zupan, J., de Cerreno, A., Paaswell, R., 2007. An evaluation of alternatives to the new york city congestion pricing plan. Regional Plan Association. 


\section{A Solution method}

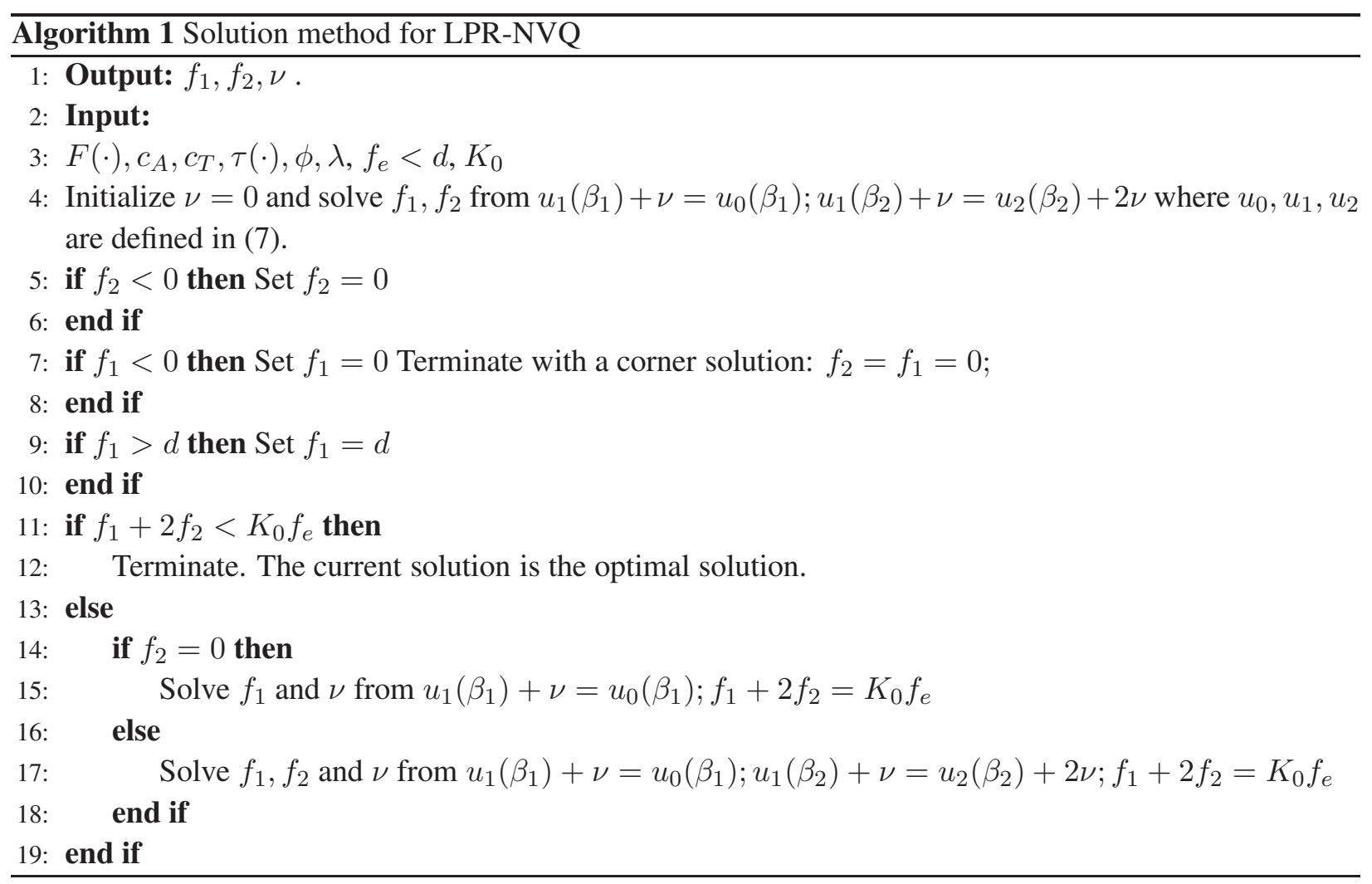

